\title{
ASOCIACIONES CIVILES, TUTELA INDIVIDUAL HOMOGÉNEA Y LAS FACULTADES REGLAMENTARIAS DE LA CoRTE SuPREMA de JuSticia dE la NacióN
}

\section{Adriel Fernández Santander}

\author{
Departamento de Derecho Procesal, Facultad de Derecho, Universidad Austral \\ afernandezsantander@austral.edu.ar
}

Recibido: 26/08/2021

Aceptado: 29/09/2021

\section{Resumen}

La reforma constitucional de 1994 introdujo cambios en la regulación del amparo en la Argentina, entre las que se destaca el empoderamiento otorgado a las asociaciones civiles para litigar en defensa de derechos colectivos. Sin una normativa legal adecuada, la Corte Suprema de Justicia de la Nación generó mecanismos procesales, mediante su actividad jurisdiccional y haciendo uso de sus facultades regulatorias, para que estas personas jurídicas impulsen acciones judiciales de tutela individual homogénea para derechos completamente divisibles e independientes. En este trabajo se relevan los hitos más importantes del camino recorrido por la Corte y se realiza un análisis crítico de este a la luz del ordenamiento jurídico vigente.

Palabras clave: acción de clase, proceso colectivo, tutela individual homogénea, derecho procesal civil, facultades regulatorias judiciales, asociaciones civiles.

\section{Nonprofit Corporations, Class Actions and Argentine Supreme Court of Justice's Regulatory Powers}

\footnotetext{
Abstract

The 1994 amendment of the Argentine Constitution passed some important changes that entitled nonprofit organizations to sue in defense of other rights with a collective impact.

Without a proper statute law, the Argentine Supreme Court designed a sui generis type of judicial process providing these corporations with the standing to sue without being the real owner of a divisible and independent claim. This paper is a description of the landmarks in
} 
the path of the Argentine Supreme Court in this field and an analysis under the parameters of the Argentine legal system.

Key words: class action, collective action, civil litigation law, judiciary regulatory powers, nonprofit corporations.

\section{Introducción ${ }^{1}$}

La Corte Suprema de Justicia de la Nación (en adelante, CSJN, la Corte, entre otros), en ejercicio de sus facultades jurisdiccionales y reglamentarias, es la precursora de los procesos de tutela individual homogénea en la Argentina.

El mundo de lo que se conoce como "justicia colectiva" ${ }^{2}$ es sumamente atractivo, quizás porque puede parecer mágico cómo con una sola resolución judicial se le pone fin al actuar ilícito de grandes entidades y se reparan los daños provocados a una multitud. Tan es así que hasta en el cine se han producido películas cuya trama gira alrededor de una acción de clase, a las que se ha referido la doctrina nacional para explicar los primeros y resonantes casos resueltos a través de esta vía.

Si bien tomó fuerza desde la reforma constitucional de 1994, la regulación de los procesos colectivos es una discusión de larga data en diversos ámbitos en nuestro país, con resultados disímiles en las distintas jurisdicciones. En algunas de ellas no existe ningún tipo de normativa; en otras, la praxis tribunalicia se rige por precedentes jurisprudenciales, mientras que algunas no cuentan con experiencia en la materia.

Como sucede en la mayoría de los asuntos jurídicos de la Argentina, resulta sumamente relevante el desarrollo que la CSJN ha generado sobre a este cauce procesal. El camino iniciado en 2006 por el fallo Mendoza $a^{3}$ y continuado en 2009 en la causa Halabi ${ }^{4}$ tuvo destacados complementos hasta el día de hoy, conformando un conjunto digno de ser estudiado.

De los cuantiosos aspectos a abordar a la hora de referirse a este tipo de

1 Agradezco los valiosos aportes a este trabajo del Dr. Gustavo Calvinho, director del Departamento de Derecho Procesal de la Universidad Austral.

2 Existen diversas explicaciones doctrinarias respecto a la terminología a emplear en la materia, las cuales se encuentran resumidamente expuestas en Lorenzetti (2017, pp. 11-13).

3 CSJN, Mendoza, Beatriz Silvia y otros c/Estado Nacional y otros s/daños y perjuicios (daños derivados de la contaminación ambiental del Río Matanza - Riachuelo), 20/06/2006, Fallos: 329:2316.

4 CSJN, Halabi, Ernesto c/Poder Ejecutivo Nacional - ley 25.873 - dto. 1563/04 s/amparo ley 16.986, 24/02/2009, Fallos: 332:111, Nro. Interno: H.270. XLII. 
procesos, quiero hacer foco en determinar qué elemento faculta a entablar una acción judicial para promover la defensa de un derecho que no es propio. ${ }^{5}$

A continuación, habré de referirme a lo actuado por la Corte, con una mirada crítica, a la luz de las normas vigentes en el ordenamiento jurídico argentino y haciendo especial hincapié en el respeto por los principios de la forma republicana de gobierno consagrada en la Constitución Nacional ${ }^{6}$ (en adelante, $\mathrm{CN}$ ), en especial la división de poderes.

Del universo que compone lo que se conoce como "justicia colectiva", solo abordaré el mundo de aquellos supuestos tratados por la Corte relativos a la tutela individual homogénea, sin desconocer que existe otro tipo de realidades susceptibles de protección. Para ser más específico, el punto concreto al que dirigiré mi atención es el modo en el que la CSJN reconoce la legitimación extraordinaria, especialmente a las asociaciones civiles en este tipo de litigios.

Este estudio se divide en dos partes. En la primera abordaré el marco normativo vigente y la elaboración jurisprudencial de la Corte. Procuraré brindar un enfoque que dé cuenta del desarrollo histórico de los conceptos relevantes en la materia, incluidas algunas iniciativas significativas que no han llegado a concretarse. En segundo término, me referiré de manera crítica al tratamiento que la judicatura le ha otorgado a la legitimación extraordinaria de las asociaciones civiles en procesos de tutela individual homogénea por no respetar las pautas constitucionales vigentes para la regulación procesal, las cuales son salvaguarda de las garantías procesales de las partes involucradas en esta clase de litigios.

Podré verificar de primera mano a lo largo del presente estudio el pensamiento formulado, quizás a modo de advertencia, por Alvarado Velloso (2010), quien afirma que

algunos jueces con vocación de protagonismo mediático han comenzado a intervenir en toda suerte de asuntos, propios de la competencia constitucional exclusiva de otros Poderes del Estado, interfiriendo con ello en la tarea de gobernar al asumir el cumplimiento de funciones que son privativas de otras autoridades. Y, de tal forma, han abandonado el juicioso acatamiento de la ley para entrar al

5 Cfr. Briseño Sierra (1966, p. 263): "[A]hí donde el titular del derecho obra por sí, siendo hábil, no debe hablarse de legitimación sino de titularidad. La legitimación sólo tiene lugar cuando es menester de un órgano o de una persona que exprese eficazmente su voluntad en el ejercicio de los derechos ajenos, cuyo titular es inhábil".

6 "Artículo 1\%.- La Nación Argentina adopta para su gobierno la forma representativa republicana federal, según la establece la presente Constitución”. 
campo del cogobierno y, aun más, ingresando a un terreno muy peligroso: el de una suerte de increíble desgobierno, ya imposible de controlar. (p. 1212)

\section{La legitimación extraordinaria de las asociaciones civiles en los supuestos de tutela individual homogénea \\ 2.1. Precisiones conceptuales}

El título de la primera parte de este trabajo requiere de algunas precisiones en cuanto al significado de las palabras allí mencionadas.

\subsubsection{Legitimación extraordinaria}

El desarrollo de la legitimación como figura relevante en un litigio judicial surge de la distinción entre dos derechos: el pretendido en un proceso y el derecho autónomo de acción.

Tradicionalmente, los sistemas jurídicos solo admitían el ejercicio del derecho a accionar a quien afirmaba ser titular, al mismo tiempo, del derecho subjetivo reclamado en el marco de un litigio judicial. Este tipo de legitimación, conocida como "ordinaria", proviene de la pretendida titularidad de un derecho subjetivo cuya tutela se exige en juicio. Se advierte así la trascendencia de la frase retórica de Couture (2010 [1950], p. 158) en la que pregunta: "¿Qué significado tendría ser titular de derechos si no se tuviera junto a ellos aptitud jurídica para defenderlos en juicio?".

Por ello, en el ámbito de un proceso jurisdiccional, lo habitual es que el magistrado pueda conceder lo solicitado a quien justifica su carácter de parte actora, con fundamento en una relación jurídica sustancial previa. ${ }^{7}$

En un sentido similar a la pregunta del maestro uruguayo, puedo cuestionarme acerca del fundamento por el cual se posee la aptitud de defender derechos en juicio sin afirmar ser el titular de estos.

Más recientemente, las normas procesales han permitido disociar los derechos de pretender y accionar en cabezas diferentes, admitiendo que alguien litigue por un derecho ajeno. Esta es, sin más, la noción de "legitimación extraordinaria”.

En palabras de Montero Aroca et al. (2001), célebre procesalista español contemporáneo, la existencia misma del concepto procura 
distinguir entre partes materiales y partes procesales, y respecto de estas segundas la legitimación resuelve la cuestión de quién puede pedir en juicio la actuación del derecho objetivo en el caso concreto y contra quién puede pedirse. [...] La legitimación adquiere entidad cuando se admite que la misma puede existir sin derecho subjetivo. (p. 82)

Esta idea también es abordada por Palacio (2017), quien explica que la legislación procesal

contempla diversos casos de legitimación anómala o extraordinaria, a los cuales caracteriza el hecho de que resultan habilitadas para intervenir en el proceso, como partes legítimas, personas ajenas a la relación jurídica sustancial que en aquél se controvierte. $(\S 81)$

Sin esta separación entre titularidad de la relación jurídica material y la posibilidad de pretender en el plano procesal, solo cabría hablar de titularidad de un derecho como puerta de acceso para promover su defensa en juicio.

Refiriéndose al ámbito específico de este estudio, Salgado (2011) nos advierte:

la distinción entre la legitimación tradicional u ordinaria y la extraordinaria radica en su disociación entre la titularidad material del derecho sustancial y la habilitación legal para disponer de él. En la ordinaria, no existirán diferencias entre quien se presenta como su titular en el plano material y quien se encuentra habilitado para su ejercicio. En la extraordinaria, en cambio, al no existir un sujeto materialmente predeterminado a disponer de los derechos colectivos -sean difusos o individuales homogéneos-, se recurre a una habilitación normativa que autoriza a determinados sujetos, y no a otros, a activar el resguardo de la prerrogativa. (pp. 146-147)

¿Cuáles serán los motivos que justifican y permiten esta facultad especial? Existen razones de política legislativa que fundamentan los extremos por los que un juez puede dictar una sentencia que incidirá sobre los derechos de alguien que no inició ni impulsó un proceso, promovido por otro sujeto en calidad de parte actora sin afirmar su titularidad.

A diferencia de la legitimación ordinaria, estos supuestos extraordinarios son habilitados no por detentar un derecho subjetivo cuya defensa se pretende en juicio, sino por una norma que permite esta posibilidad y torna eficaz la tutela jurisdiccional al operarse de esta manera. ${ }^{8}$ 


\subsubsection{Tutela individual homogénea}

El concepto con el que se titula este apartado está en íntima relación con lo explicado en el punto anterior, porque, tanto para la doctrina como para la jurisprudencia, la tutela individual homogénea se vincula inexorablemente con el concepto de "legitimación extraordinaria".

Salgado (2011, p. 1) la define como la "posibilidad de dar respuesta, con valor de cosa juzgada, a un número plural de reclamos en un solo proceso judicial, aunque éstos, en teoría, podrían ser postulados o defendidos en tantos litigios como personas integren el conjunto".

Según lo expresado por Giannini (2015)

El típico ejemplo es el de los daños y perjuicios ocasionados masivamente en razón de productos en mal estado, catástrofes, explosiones, etc. [...] Pero las hipótesis no se limitan exclusivamente a los supuestos de mass tort litigation. Existe una variadísima gama de pretensiones en las que resulta materialmente viable la diferencia de trato entre los distintos sujetos de la clase. Por ejemplo: a) pretensiones de hacer -v.gr., remover personas indebidamente colocadas en un registro o prohibir la utilización de la información volcada un una base de datos más allá de los fines específicos para los que fue voluntariamente aportada (hábeas data, otorgar a determinados sujetos los beneficios de las prestaciones médicas basadas en la seguridad social, entregar alimentos o insumos educativos a niños de una región necesitada, construir viviendas, entregar medicamentos para enfermos de determinadas características, etc.-; b) acciones de cesación de actividades indebidas -v.gr., interdicción de descuentos o rebajas salariales. (§ 544 Quinquies)

La peculiaridad de esta figura, frente a otras en las que se admite la configuración plural de alguna de las partes,

es que los integrantes del grupo no tendrán necesidad de comparecer al proceso desde un comienzo [...] e incluso podrán sumarse personas [...] cuando el proceso haya culminado. Un tercero, legitimado extraordinario, propondrá un litigio representativo y actuará en defensa de los derechos de todos los integrantes del grupo, ausentes o presentes en el reclamo. (Giannini, 2015, §544 Quinquies)

Más adelante ahondaré en las características que la jurisprudencia de la CSJN y la doctrina han otorgado a este supuesto de tutela.

\subsubsection{Asociaciones civiles}

Dentro del catálogo de personas jurídicas privadas se incluye en el inciso b) del 
artículo 148 del Código Civil y Comercial de la Nación (en adelante, CCCN) ${ }^{9}$ a las asociaciones civiles.

Esta misma norma, entre los artículos 168 y 186, regula los aspectos específicos de estas.

Tobías (2018) define a la asociación civil como

persona jurídica privada que se forma con la unión estable de una pluralidad de personas (independiente en su existencia del cambio de miembros), que tiene una constitución corporativa y un nombre colectivo, cuyo objeto no debe ser contrario al interés general o al bien común, no puede perseguir el lucro como fin principal para sí, ni tener por fin el lucro para sus miembros o terceros. (Capítulo XXI, Sección 1a)

La importancia para los supuestos de legitimación extraordinaria que trataré en este trabajo es, como bien lo expresa Salgado (2011), que

la asociación actuará en nombre de una clase o grupo de personas, circunstancia que podrá ser coincidente o no con la nómina de personas vinculadas a ella. Es decir, no actuará por mandato de sus socios sino por una autodesignación como legitimada; luego se podrá observar que la clase representada en el proceso estará conformada por algunos de los asociados y por terceros ajenos a la entidad, y podrá ocurrir que determinados socios no se encuentren comprendidos en la clase de que se trata. (pp. 166-167)

Cuando exponga sobre la regulación del artículo 43 de la CN, de la inclusión allí de esta clase de personas jurídicas y lo interpretado por la CSJN en cuanto al alcance de la cláusula, resultará clara la importancia del análisis de esta figura.

\subsubsection{Recapitulación}

Luego del desarrollo de los conceptos antes detallados, procuraré realizar una breve síntesis conjunta, que es oportuna para comprender con precisión el objeto específico del presente estudio.

De todas las alternativas posibles en las que un sujeto se presenta en un juicio relativo a un derecho ajeno, solo habré de referirme a los supuestos en los que esa legitimación extraordinaria es ejercida por una asociación civil que se

Ley 26994 de Código Civil y Comercial de la Nación, BO 08/10/2014. 
designa a sí misma para tutelar derechos completamente divisibles e independientes, sin mediar ningún tipo de acuerdo previo con sus titulares (Salgado, 2011, p. 1) o, como se explicará más adelante, sin una ley que así lo prevea.

La importancia de este estudio radica en que es un verdadero desafío justificar que una asociación plantee una pretensión procesal en virtud de una relación jurídica en la que no es parte y sin que se le haya conferido un mandato contractual o representación legal que le otorgue dicha facultad. Fallar en ese cometido afectaría, entre otros, el derecho de defensa de quienes podrían estar legitimados y desconocen una pretendida representación, de quienes resulten parte demandada en un proceso o de aquellos que, sin intervenir en este, puedan ser alcanzados por los efectos derivados en él (Lorenzetti, 2017, pp. 206-207).

Por ello, como afirma Lorenzzeti (2017, p. 206), "[1]a legitimación para obrar, que es de obligado análisis en todo juicio a fin de evitar soluciones nulas, cobra mayor trascendencia en los planteos colectivos".

En el mismo sentido, Verbic (2017, pp. 301-302) sostiene que "[l]a legitimación para promover la tutela judicial colectiva de derechos reviste fundamental importancia, a punto tal de haber sido considerada por autorizada doctrina como el verdadero talón de Aquiles de cualquier sistema de protección de este tipo".

Por cierto, los dos autores antes citados son promotores de este tipo de procesos y advierten este riesgo que traigo a colación.

\section{Fisonomía argentina de la tutela individual homogénea: jurisprudencia, acordadas, normas vigentes e iniciativas legislativas}

La reforma constitucional de 1994 elevó el estatus de la regulación de la acción de amparo e introdujo novedades y modificaciones a esta. ${ }^{10}$

A los efectos del presente estudio, cabe destacar que el artículo 43 de la CN otorgó de manera genérica una legitimación activa al afectado, al defensor del pueblo y a las asociaciones civiles registradas para promover procesos en defensa de derechos de incidencia colectiva, sin una determinación precisa de los extremos de dicha participación.

Textualmente, la $\mathrm{CN}$ dispone en los primeros dos párrafos de la norma citada lo siguiente:

10 Un excelente análisis y resumen de la regulación histórica del amparo y cómo fue plasmado en el artículo 43 de la CN puede encontrarse en Gelli (2018a, pp. 786-824). 
Toda persona puede interponer acción expedita y rápida de amparo, siempre que no exista otro medio judicial más idóneo, contra todo acto u omisión de autoridades públicas o de particulares, que en forma actual o inminente lesione, restrinja, altere o amenace, con arbitrariedad o ilegalidad manifiesta, derechos y garantías reconocidos por esta Constitución, un tratado o una ley. En el caso, el juez podrá declarar la inconstitucionalidad de la norma en que se funde el acto u omisión lesiva.

Podrán interponer esta acción contra cualquier forma de discriminación y en lo relativo a los derechos que protegen al ambiente, a la competencia, al usuario y al consumidor, así como a los derechos de incidencia colectiva en general, el afectado, el defensor del pueblo y las asociaciones que propendan a esos fines, registradas conforme a la ley, la que determinará los requisitos y formas de su organización [...].

Si bien la norma no lo plantea de manera expresa, existe una conceptualización tripartita de los bienes sobre los que pueden recaer los derechos que pueden protegerse a través de una acción de amparo, la cual fue adoptada por la jurisprudencia y valorada positivamente por la doctrina mayoritaria.

A continuación, abordaré los aspectos más relevantes hoy de la defensa de uno de esos bienes -los derechos individuales homogéneos-, impulsada por asociaciones civiles. Entre ellos, tiene un lugar preponderante la tarea realizada por la CSJN a través de su jurisprudencia y del dictado de dos acordadas, imprimiendo una pretendida operatividad a las disposiciones genéricas del artículo 43 de la $\mathrm{CN}$, sin contar con una reglamentación clara y completa de todos los institutos procesales en juego. También resulta apropiado relevar la normativa vigente y los proyectos de legislación discutidos en torno a la materia.

Cabe aclarar que, como recorte metodológico, solo describiré el desarrollo de la jurisprudencia a partir del año 2009, momento en el que los fallos de la CSJN receptaron el concepto "derechos individuales homogéneos". No desconozco, sin embargo, un importante desarrollo previo a dicha fecha, del cual existen innumerables reseñas. ${ }^{11}$

Sobre esta etapa, afirma Salgado (2011):

en líneas generales, se les ha reconocido su legitimación sobre la base de lo normado por el art. 43, párr. $2^{\circ}$, de la Const. Nacional. Entendemos que, en esos precedentes en que aquella aptitud para demandar les fue desconocida, en realidad se verificaba una deficiencia en su representación adecuada, o bien una

11 Ver Lorenzetti (2017, pp. 44-60) y Salgado (2011, pp. 169-177). 
ausencia de caso o controversia [...] por el no reconocimiento de los derechos individuales homogéneos como un caso susceptible de ser resuelto por los tribunales. (p. 177)

\subsection{Derechos individuales, colectivos e individuales homogéneos. El caso Halabi (2009) ${ }^{12}$}

En la instancia del recurso extraordinario interpuesto y concedido en el caso Halabi, se discutía únicamente el alcance erga omnes que la sentencia apelada le había otorgado a la decisión del litigio. ${ }^{13}$ Por ello, el alto tribunal expresó

para la dilucidación de este aspecto, según los propios términos en que ha sido formulado el cuestionamiento, es necesario determinar cuál es la naturaleza jurídica del derecho cuya salvaguarda se procuró mediante la acción deducida, quiénes son los sujetos habilitados para articularla, bajo qué condiciones puede resultar admisible y cuáles son los efectos que derivan de la resolución que en definitiva se dicte. ${ }^{14}$

La CSJN condensa en los considerandos 10 a 13 del paradigmático Halabi su interpretación en torno a lo que entiende por "derechos de incidencia colectiva” en el marco del artículo 43 de la CN. Según la postura adoptada por la Corte, la heterogeneidad de la naturaleza de los derechos en juego en cuanto a la legitimación procesal para su defensa permite "delimitar con precisión tres categorías de derechos: individuales, de incidencia colectiva que tienen por objeto bienes colectivos, y de incidencia colectiva referentes a intereses individuales homogéneos". ${ }^{15}$

Recuerda Gozaíni (2018, p. 311) que "[e]sta triple categorización de los derechos se encuentra en el Código Modelo para Iberoamérica, aprobado en el año 2002 por la Asamblea del Instituto Iberoamericano de Derecho Procesal".

El caso en análisis se detiene inicialmente a recordar que la regla tradicional en materia de legitimación es que su tutela jurisdiccional está en cabeza del titular de un derecho que recae sobre un bien jurídico individual. Esa afirmación, según la Corte,

12 Recomiendo el análisis del caso presente, entre otros, en Dalla Vía (2009) y en Sagüés (2009).

13 Cfr. Halabi, considerando 7.

14 Ídem, considerando 8.

15 Ídem, considerando 9. 
no cambia por la circunstancia de que existan numerosas personas involucradas, toda vez que se trata de obligaciones con pluralidad de sujetos activos o pasivos, o supuestos en los que aparece un litisconsorcio activo o pasivo derivado de la pluralidad de sujetos acreedores o deudores, o bien una representación plural. ${ }^{16}$

Este tipo de legitimación ordinaria es el que se protegió, según el alto tribunal, en sus precedentes Siri ${ }^{17}$ y $\mathrm{Kot}^{18}$, cuya salvaguarda se encuentra proporcionada por el párrafo primero del artículo 43 de la CN. Asimismo, concluye en que la acción de amparo "está destinada a obtener la protección de derechos divisibles, no homogéneos y se caracteriza por la búsqueda de la reparación de un daño esencialmente individual y propio de cada uno de los afectados". ${ }^{19}$

La novedad surge al desarrollar los alcances de los dos tipos de derechos de incidencia colectiva enunciados: a) los que tienen por objeto bienes colectivos; y b) los referentes a bienes individuales homogéneos.

Sobre la primera categoría, entiende que se procura "la tutela de un bien colectivo, lo que ocurre cuando éste pertenece a toda la comunidad, siendo indivisible y no admitiendo exclusión alguna", ${ }^{20}$ lo cual fundamenta la legitimación extraordinaria de los sujetos enumerados en la cláusula constitucional. En esta clase de supuestos, si bien no hay directamente derechos subjetivos en juego, recuerda Lorenzetti $(2017$, p. 22) que "la lesión a este tipo de bienes puede tener una repercusión sobre el patrimonio individual".

Como consecuencia de lo anterior, para promover este tipo de acciones, el mismo autor sostiene que

la pretensión debe ser focalizada en la incidencia colectiva del derecho. Ello es así porque la lesión a este tipo de bienes puede tener una repercusión sobre el patrimonio individual, como sucede en el caso del daño ambiental, pero esta última acción corresponde a su titular y resulta concurrente con la primera. (Lorenzetti, 2017, p. 22)

Queda delimitada una clara línea que diferencia al amparo para procurar la tutela de bienes enteramente individuales de los supuestos en los que está en juego uno colectivo.

16 Ídem, considerando 10.

17 Siri, Ángel s/interpone recurso de hábeas corpus, 27/12/1957, Fallos: 239:461.

18 Kot, Samuel S.R.L. s/recurso de hábeas corpus, 05/09/1958, Fallos: 241:291.

19 Ídem.

20 Ídem, considerando 11. 
Esto último no sucede, según la CSJN, para el segundo tipo de derecho de incidencia colectiva: el relativo a bienes individuales homogéneos. En los considerandos 12 y 13 se esbozan los lineamientos esenciales para procurar su tutela.

Según la Corte, existe una particularidad especial en "el caso de los derechos personales o patrimoniales derivados de afectaciones al ambiente y a la competencia, de los derechos de los usuarios y consumidores como de los derechos de sujetos discriminados". ${ }^{21}$ Se explica que se estaría ante supuestos similares a los abordados en el considerando 10 del fallo -derechos individuales enteramente divisibles-, pero con "un hecho, único o continuado, que provoca la lesión a todos ellos y por lo tanto es identificable una causa fáctica homogénea”. ${ }^{22}$

En este importante precedente se encuentra que esta situación común que produce el daño es la que justifica la celebración de un solo proceso para la determinación de responsabilidades con efectos expansivos del caso juzgado a quienes no intervinieron en calidad de parte, particularizando en un momento posterior la cuantía de la reparación para cada uno de los afectados.

El considerando 13 sintetiza lo anteriormente reseñado y enuncia una especie de protonorma para plantear procesos de tutela individual homogénea, motivo por el cual se transcribe íntegramente

Que la procedencia de este tipo de acciones requiere la verificación de una causa fáctica común, una pretensión procesal enfocada en el aspecto colectivo de los efectos de ese hecho y la constatación de que el ejercicio individual no aparece plenamente justificado. Sin perjuicio de lo cual, también procederá cuando, pese a tratarse de derechos individuales, exista un fuerte interés estatal en su protección, sea por su trascendencia social o en virtud de las particulares características de los sectores afectados.

El primer elemento es la existencia de un hecho único o complejo que causa una lesión a una pluralidad relevante de derechos individuales.

El segundo elemento consiste en que la pretensión debe estar concentrada en los efectos comunes y no en lo que cada individuo puede peticionar, como ocurre en los casos en que hay hechos que dañan a dos o más personas y que pueden motivar acciones de la primera categoría. De tal manera, la existencia de causa o controversia, en estos supuestos, no se relaciona con el daño diferenciado que cada sujeto sufra en su esfera, sino con los elementos homogéneos que tiene esa pluralidad de sujetos al estar afectados por un mismo hecho.

21 Ídem, considerando 12.

22 Ídem. 


\begin{abstract}
Como tercer elemento es exigible que el interés individual considerado aisladamente, no justifique la promoción de una demanda, con lo cual podría verse afectado el acceso a la justicia. Sin perjuicio de ello, como se anticipó, la acción resultará de todos modos procedente en aquellos supuestos en los que cobran preeminencia otros aspectos referidos a materias tales como el ambiente, el consumo o la salud o afectan a grupos que tradicionalmente han sido postergados, o en su caso, débilmente protegidos. En esas circunstancias, la naturaleza de esos derechos excede el interés de cada parte, y al mismo tiempo, pone en evidencia la presencia de un fuerte interés estatal para su protección, entendido como el de la sociedad en su conjunto. En tal sentido, los arts. 41, 42 y 43, párr. 2, CN., brindan una pauta en la línea expuesta. ${ }^{23}$
\end{abstract}

Se establecen así los requisitos de procedencia para este tipo de acciones, los cuales son empleados por primera vez para dar un alcance especial al planteo que el actor, Dr. Halabi, ${ }^{24}$ había incoado en defensa únicamente de sus propios derechos. ${ }^{25}$

Como ya se ha mencionado, del amplio espectro detallado por la CSJN en este precedente, solo me encuentro abordando los supuestos relativos a intereses individuales homogéneos, en los que principalmente existe una multiplicidad de sujetos titulares de un derecho enteramente individual que se encuentran afectados por una causa común. ${ }^{26}$

En abstracto, cada uno podría accionar en solitario contra quien lesiona a todos al no verificarse los supuestos del litisconsorcio necesario ${ }^{27} \mathrm{y}$, teóricamente, podría existir multiplicidad de procesos con distintos actores e idénticas pre-

23 Ídem, considerando 13.

24 Cfr. Ídem, considerando 14.

25 Según surge de la lectura del fallo, en el considerando 1. Asimismo, habría sido la Sala II de la Cámara Nacional de Apelaciones en lo Contencioso Administrativo Federal la que introdujo la pretensión colectiva. Según se relata en el considerando 4, "estimó que la legitimación del actor no excluia la incidencia colectiva de la afectación a la luz del $2^{\circ}$ párrafo del art. 43 de la Constitución Nacional por lo que la sentencia dictada en tales condiciones debía aprovechar a todos los usuarios que no han participado en el juicio" (en cursiva figura lo transcripto por la Corte del fallo de la Cámara).

26 Además de los derechos relativos a bienes individuales homogéneos, quiero traer a colación unas pocas líneas que condensan muy bien las diferencias entre los conceptos que a continuación se expondrán. Estas figuran en la primera edición de Lorenzetti (2010, p. 19): "Derechos sobre bienes jurídicos individuales: [en los que] el interés es individual, la legitimación también, y cada interés es diverso de otros; cada titular inicia una acción y obtiene sentencia en un proceso bilateral [...]. Es el modelo tradicional del litigio singular [...]. Derechos sobre bienes jurídicos colectivos: [en los cuales] el bien afectado es colectivo, el titular del interés es el grupo y no un individuo particular".

27 Regulado en el artículo 89 del Código Procesal Civil y Comercial de la Nación (en adelante, CPCCN), el cual establece: "Art. 89.- Cuando la sentencia no pudiere pronunciarse útilmente más que con relación a varias partes, éstas habrán de demandar o ser demandadas en un mismo proceso. Si así no sucediere, el juez de oficio o a solicitud de cualquiera de las partes ordenará, antes de 
tensiones y partes demandadas, pero, por diversos motivos, se opta por unificar los procesos en un solo expediente. ${ }^{28}$

Resulta sumamente apropiado para este estudio reseñar el presente caso porque si bien la acción es deducida por un particular en interés propio -el afectado-, la CSJN admite la posibilidad de que también el Defensor del Pueblo y las asociaciones, ambos mencionados en el artículo 43 de la CN, puedan deducir pretensiones colectivas similares a las planteadas en este precedente. ${ }^{29}$

Cabe concluir este apartado con lo mencionado por la CSJN respecto a la inexistencia de una norma que regule los procesos colectivos:

debe existir una ley que determine cuándo se da una pluralidad relevante de individuos que permita ejercer dichas acciones, cómo se define la clase homogénea, si la legitimación corresponde exclusivamente a un integrante de la clase o también a organismos públicos o asociaciones, cómo tramitan estos procesos, cuáles son los efectos expansivos de la sentencia a dictar y cómo se hacen efectivos. ${ }^{30}$

Sin embargo, no considera que este déficit sea un obstáculo -aunque sí un claro retardo en las obligaciones del Poder Legislativo que debe ser subsanado cuanto antes-, porque la cláusula constitucional en análisis "es claramente operativa y es obligación de los jueces darle eficacia, cuando se aporta nítida evidencia sobre la afectación de un derecho fundamental y del acceso a la justicia de su titular". 31

Entonces, según explica Lorenzetti (2017, p. 128), "[1]a fuente de los procesos colectivos puede ubicarse en el bloque de constitucionalidad [...]”, siendo el amparo una garantía reconocida por la Constitución Nacional y la Convención Americana sobre Derechos Humanos, lo cual transforma a las disposiciones que lo consagran sendas normas operativas que, ante la falta de desarrollo legislativo por parte del Congreso, pueden ser integradas - no solo interpretadas y aplicadas- según lo que el juez considere oportuno para cada caso. ${ }^{32}$

dictar la providencia de apertura a prueba, la integración de la litis dentro de un plazo que señalará, quedando en suspenso el desarrollo del proceso mientras se cita al litigante o litigantes omitidos".

28 No habré de referirme a los supuestos de legitimación pasiva colectiva que si bien son tratados por la doctrina, no han tenido repercusión en la jurisprudencia de la Corte Suprema de Justicia de la Nación y no son conducentes a los efectos del presente estudio.

29 Cfr. Halabi, considerando 19 in fine.

30 Cfr. Ídem, considerando 12.

31 Ídem.

32 Ver Lorenzetti (2017, p. 79): “Conviene aclarar que cuando se habla de operatividad de las normas declarativas de derecho, se está aludiendo a la posibilidad de que éstas sean autoejecutorias, que 
Por lo tanto, la existencia de derechos sobre bienes individuales homogéneos habilitaría a los magistrados a brindarles una tutela que surge directamente de las normas constitucionales y convencionales, supliendo la discreción de los magistrados a la inexistencia de leyes procesales. ${ }^{33}$

A partir de las apreciaciones realizadas por la Corte, resulta de vital importancia lo manifestado por ella en el considerando 20 del fallo. A continuación se transcribe en su totalidad por entender que allí se plasmó el nuevo paradigma procesal que luego fue desarrollando la CSJN hasta llegar a su configuración actual

\begin{abstract}
Ante la ya advertida ausencia de pautas adjetivas mínimas que regulen la materia, se torna indispensable formular algunas precisiones, con el objeto de que ante la utilización que en lo sucesivo se haga de la figura de la "acción colectiva" que se ha delineado en el presente fallo se resguarde el derecho de la defensa en juicio, de modo de evitar que alguien pueda verse afectado por una sentencia dictada en un proceso en el que no ha tenido la posibilidad efectiva de participar. Es por ello que esta Corte entiende que la admisión formal de toda acción colectiva requiere la verificación de ciertos recaudos elementales que hacen a su viabilidad tales como la precisa identificación del grupo o colectivo afectado, la idoneidad de quien pretenda asumir su representación y la existencia de un planteo que involucre, por sobre los aspectos individuales, cuestiones de hecho y de derecho que sean comunes y homogéneas a todo el colectivo. Es esencial, asimismo, que se arbitre en cada caso un procedimiento apto para garantizar la adecuada notificación de todas aquellas personas que pudieran tener un interés en el resultado del litigio, de manera de asegurarles tanto la alternativa de optar por quedar fuera del pleito como la de comparecer en él como parte o contraparte. Es menester, por lo demás, que se implementen adecuadas medidas de publicidad orientadas a evitar la multiplicación o superposición de procesos colectivos con un mismo objeto a fin de aventar el peligro de que se dicten sentencias disímiles o contradictorias sobre idénticos puntos.
\end{abstract}

Como puede observarse, el alto tribunal establece pautas procesales genéricas para un litigio colectivo, las cuales serán aplicadas luego por la decisión discrecional del juez que intervenga en cada supuesto de tutela individual homogénea. A los efectos del presente estudio, resulta de especial interés que el requisito de "idoneidad de quien pretenda asumir su representación" sea elevado por la Corte al estatus de presupuesto de admisibilidad que, de no verificarse,

habiliten expresamente el uso y goce del derecho declarado".

33 Cfr. Lorenzetti (2017, p. 83). 
podría presumirse que le cabría al magistrado la posibilidad de rechazo in limine de la demanda promovida. ${ }^{34}$

La CSJN, en muchas ocasiones, se muestra con una preocupación por la inexistencia de una ley procesal específica que le permita a la justicia tramitar expedientes relativos a la materia. Sin embargo, en los hechos, siempre encuentra algún justificativo o excusa para intervenir a pesar de este déficit. Por ejemplo, como más adelante se comentará, en el año 2016 la Corte dictó la Acordada 12, creando un Reglamento relativo a diversos aspectos de tramitación de la mayoría de los procesos colectivos. En el punto IV, en sintonía con el considerando 9 de Halabi, dispone que este "tendrá vigencia hasta tanto el Poder Legislativo Nacional sancione una ley que regule este tipo de procesos".

Puede verse cómo, por un lado, el alto tribunal admite la necesidad de una norma legal para tramitar procesos colectivos, pero, por el otro, genera sus propias disposiciones por considerarse habilitada para suplir esta carencia de manera pretoriana. ${ }^{35}$

\subsection{Desarrollo jurisprudencial y acordadas dictadas por la CSJN}

\subsubsection{PADEC (2013) $)^{36}$}

Ante una excepción de falta de legitimación activa declarada procedente por las instancias inferiores, en este precedente la Corte aplicó por vez primera ${ }^{37}$ lo reglado en Halabi para una acción incoada por una asociación civil, revocó el

34 Tal como lo prevé el artículo 337 del CPCCN: "Los jueces podrán rechazar de oficio las demandas que no se ajusten a las reglas establecidas, expresando el defecto que contengan [...]".

35 Cfr. Halabi, considerando 15.

36 CSJN, PADEC c/Swiss Medical S.A. s/nulidad de cláusulas contractuales, 21/08/2013, Nro. Interno: P.361.XLIII, Id SAIJ: FA13000127. Se recomienda la lectura de la reseña realizada en Ylarri (2014).

37 El precedente será citado en diversas oportunidades por la Corte. Por la masividad de sus efectos, haré referencia al caso CEPIS, en el cual se sintetizó PADEC en los siguientes términos: "Es menester recordar que, en recientes precedentes, esta Corte reconoció que, de acuerdo a las disposiciones del artículo 43 de la Constitución Nacional, las asociaciones de usuarios y consumidores se encuentran legitimadas para iniciar acciones colectivas relativas a derechos de incidencia colectiva referentes a intereses individuales homogéneos, incluso de naturaleza patrimonial, en la medida en que demuestren: la existencia de un hecho único susceptible de ocasionar una lesión a una pluralidad de sujetos; que la pretensión este concentrada en los 'efectos comunes' para toda la clase involucrada; y que de no reconocerse la legitimación procesal podría comprometerse seriamente el acceso a la justicia de los integrantes del colectivo cuya representación se pretende asumir" (CSJN, Centro de Estudios para la Promoción de la Igualdad y la Solidaridad y otros c/Ministerio de Energía y Minería s/amparo colectivo, 18/06/2016, Nro. Interno: FLP 8399/2016/CS1, Id SAIJ: FA16000098, considerando 10). 
fallo y remitió el expediente al tribunal de primera instancia para que se sustancie el proceso según las expresas instrucciones que se brindan en este. ${ }^{38}$

No constan en el fallo las razones aducidas por la demandada para plantear la excepción mencionada, pero sí los motivos por los que el juez de primera instancia y la cámara de apelaciones hicieron lugar a esta. En general, se entendió que la asociación civil PADEC no podía impulsar válidamente el proceso por no tratarse de un supuesto de tutela individual homogénea. ${ }^{39}$

La pretensión de la actora, que se presentaba en defensa de derechos ajenos, resultaba ser la declaración de nulidad de una cláusula del contrato de adhesión mediante el cual la demandada, una empresa de medicina prepaga, podía modificar de manera unilateral el canon mensual abonado por terceros, los afiliados a dicha empresa, que no intervinieron en este juicio. De esta manera, se dejarían sin efecto los aumentos ya fijados y cancelados, devolviéndose así las sumas indebidamente percibidas.

Retomando lo dicho en Halabi, la Corte encuentra que se verifican los requisitos establecidos en dicho precedente para admitir el proceso colectivo y reconocer la legitimación extraordinaria, revirtiendo así lo dispuesto por el tribunal inferior. ${ }^{40}$ Es explícito el reconocimiento a las asociaciones civiles para promover acciones de tutela individual homogénea que surge del considerando 12, en el que expresa:

en cuanto a los sujetos habilitados para demandar en defensa de derechos como los involucrados en el sub lite, es perfectamente aceptable dentro del esquema de nuestro ordenamiento que determinadas asociaciones deduzcan, en los términos del ya citado segundo párrafo del artículo 43, una acción colectiva con análogas características y efectos a la existente en el derecho norteamericano. ${ }^{41}$

38 Cfr. PADEC, considerando 12 y parte resolutiva de la sentencia.

39 Cfr. Ídem, considerando. 2, el que textualmente manifiesta: "Que para decidir como lo hizo, el tribunal a quo consideró que el derecho invocado por la actora no constituía un derecho de incidencia colectiva. Por el contrario, entendió que los intereses involucrados en el caso eran patrimoniales y divisibles, que podían resultar contradictorios o confusos, y que su homogeneidad era solo aparente. Agregó que no surgía del expediente que todos los afiliados hubieran avalado la promoción de la demanda, y consideró cuanto menos riesgoso dejar librada su defensa a una asociación de consumidores. Al respecto, entendió que la afectación de derechos subjetivos proyectada a un grupo determinado de personas no necesariamente conllevaba a un derecho de incidencia colectiva, sino más bien a una sumatoria de derechos subjetivos y que, en estos casos, correspondía ser extremadamente cauto, puesto que se corría el riesgo de sustituir la voluntad del interesado a quien le correspondía en forma exclusiva el ejercicio y tutela de sus derechos. En consecuencia, concluyó que el carácter divisible y no homogéneo de los intereses en juego determinaba la falta de legitimación de la actora para demandar la nulidad de las cláusulas contractuales impugnadas”. Ver también considerando 7.

40 Cfr. Ídem, considerandos 11 y 12.

41 Cfr. considerando 19 in fine del fallo Halabi. 
Entre sus argumentos, resulta de especial interés para la CSJN que el objeto social de la entidad es idóneo para impulsar la tutela pretendida ${ }^{42}$ según los requisitos previstos en el considerando 20 de Halabi.

Es llamativo que, solo al concluir con su análisis, la CSJN trae a colación que en la legislación vigente -Ley 24240 de defensa del consumidor- se habilita a las asociaciones civiles de consumidores a realizar planteos colectivos. ${ }^{43}$ En otras palabras, la legitimación extraordinaria de este tipo de entidades está amparada, según la Corte, de manera principal en el artículo 43 de la CN y en el caso Halabi, aunque también existen normas de rango infraconstitucional que así lo prevén.

\subsubsection{Acordada 32/2014, Reglamento de Registro Público de Procesos Colectivos ${ }^{44}$}

En una primera lectura, parece ser bastante tangencial la importancia de esta acordada dictada por la CSJN para el objeto de este estudio.

A 5 años de que Halabi viera la luz, la Corte creó un Registro Público de Procesos Colectivos para evitar la tramitación de causas con igual o similar objeto ante diversos órganos judiciales. ${ }^{45}$

Es cierto que la finalidad perseguida parecería loable, ya que procuraba evitar el dictado de sentencias contradictorias sobre los mismos asuntos litigiosos. Sin embargo, quizás fue solo un resultado lógico del devenir de la jurisprudencia de la Corte hasta el momento y una consecuencia esperable de la falta de acatamiento por parte de los tribunales inferiores a los precedentes por ella elaborados.

Por lo tanto, con el dictado de la acordada solo se dio cierto orden y registración al trámite de procesos colectivos que, luego de Halabi y PADEC, se multiplicaban dentro de los distintos fueros del Poder Judicial de la Nación, con el peligro del dictado de resoluciones judiciales contrapuestas ya mencionado. ${ }^{46}$

Analizando las disposiciones específicas del Reglamento, este cobra una especial relevancia respecto a la legitimación extraordinaria de las asociaciones, porque la norma establece que el juzgado interviniente debe pronunciarse

42 Cfr. PADEC, considerando 13.

43 Cfr. Ídem, considerandos 15 y 16.

44 CSJN, Acordada 32/2014, 01/10/2014, AR/LCON/6CE4.

45 Esta novedad fue anunciada por la Corte en Municipalidad de Berazategui c/Cablevisión S. A. s/amparo, 23/09/2014, Nro. Interno: M. 1145. XLIX., considerando 7 in fine, Id SAIJ: FA14000143.

Ver Acordada 32/2014, considerando 1. 
sobre la idoneidad del representante del colectivo involucrado en el caso correspondiente.

¿Bajo qué criterios? En el punto 1 del Reglamento, la Corte dispone que deben acatarse las "definiciones" que surgen de Halabi y PADEC para los supuestos de tutela de intereses individuales homogéneos. ${ }^{47}$ Hasta el momento del dictado de la acordada, podría decirse que la idoneidad para accionar en este tipo de procesos alegando legitimación extraordinaria está condicionado por la relación entre el objeto estatutario de la asociación civil y la naturaleza de la pretensión.

\subsubsection{DEFEINDER (2014) ${ }^{48}$}

El proceso judicial en materia de derecho del consumidor que desemboca en este fallo de la CSJN es impulsado por una asociación civil que si bien cuenta con una inscripción genérica para funcionar como persona jurídica, no se halla incorporada en el Registro Nacional de Asociaciones de Consumidores (ReNAC). ${ }^{49}$ Es decir, solo cumple con los recaudos del Código Civil vigente hasta 2015 relativos a las asociaciones civiles y la normativa local específica para cualquier persona jurídica. Ante la demanda incoada, se interpone en el caso la excepción de falta de legitimación activa.

La Ley de Defensa del Consumidor establece como requisito de legitimación para las asociaciones de consumidores solicitar y obtener autorización para funcionar. ${ }^{50} \mathrm{Si}$ esta es otorgada, las entidades pasan a ser parte del ReNAC.

Ante esta circunstancia, la Corte interpreta que la registración "conforme a la ley" ordenada por el artículo 43 de la $\mathrm{CN}$ es indispensable para poseer la legitimación extraordinaria que otorga dicha cláusula constitucional.

En general, ese recaudo se acredita cumpliendo con lo previsto en la legislación de fondo y en la normativa sobre personas jurídicas de la jurisdicción local

47 "1. En el Registro se inscribirán ordenadamente todos los procesos colectivos, tanto los que tengan por objeto bienes colectivos como los que promuevan la tutela de intereses individuales homogéneos con arreglo a las concordes definiciones dadas por esta Corte en los precedentes 'Halabi' (Fallos: 332:111) y P.361.XLIII 'PADEC c/Swiss Medical S.A. s/nulidad de cláusulas contractuales', sentencia del 21 de agosto de 2013”.

48 CSJN, Asociación Civil DEFEINDER c/Telefónica de Argentina S.A. s/proceso de conocimiento, 27/11/2014, Nro. Interno: A.803. XLVI.

49 Registro creado por el Decreto 1798/1994, reglamentario de la Ley 24240, BO 18/10/1994.

50 Cfr. artículos 55 y siguientes de la Ley 24240 de Defensa al Consumidor, BO 15/10/1993, norma que será comentada más adelante en este trabajo. 
en la que se constituyera una asociación civil. De manera particular, en caso de existir una ley especial que imponga requisitos especiales de registración, estos son insoslayables para pretender en un proceso colectivo.

Dicho razonamiento, aplicado a este caso que versa sobre los derechos de usuarios y consumidores, impone la obligación de estar incluido en el ReNAC. ${ }^{51}$

\subsubsection{SUTPLA (2015) ${ }^{52}$}

La CSJN desconoció la legitimación extraordinaria a una asociación sindical patrocinadora de un grupo de personas privadas de la libertad que solo acreditaba en el expediente haber iniciado los trámites necesarios para obtener la personaría gremial, sin obtener la incorporación como entidad gremial según la Ley $23551^{53}$ al momento de promover la demanda.

Con mayor precisión, la Corte delimita en este precedente el momento específico desde el cual una asociación -sindical en este caso- puede ser parte en un proceso de tutela individual homogénea. Este es la incorporación por parte de la autoridad competente en el registro general o especial, en caso de existir. Por tanto, la mera iniciación de los trámites correspondientes no habilita a presentarse en juicio.

\subsubsection{Acordada 12/2016, Reglamento de Actuación en Procesos Colectivos ${ }^{54}$}

En esta norma, la Corte ratifica la Acordada 32 dictada en 2014, aporta mayores precisiones e incorpora elementos del amplio desarrollo jurisprudencial del bienio transcurrido entre ambas disposiciones.

51 Bien se explica en el dictamen de la Procuración General de la Nación que "[l]a resolución 1139/97 de la Secretaria de Industria, Comercio y Minería acotó la obligatoriedad de la inscripción en el Registro Nacional mencionado sólo a aquellas asociaciones de consumidores que funcionaran en el ámbito nacional y que acreditasen su actuación efectiva en más de una jurisdicción, ya sea provincial o de la Ciudad Autónoma de Buenos Aires. Las restantes asociaciones que tuvieran sede y desarrollaran sus actividades únicamente en ámbitos locales, debían, conforme esa resolución, inscribirse en los registros creados en cada jurisdicción” (apartado IV, página 5 del dictamen).

52 CSJN, Sindicato Único de Trabajadores Privados de la Libertad Ambulatoria c/Estado Nacional - Ministerio de Justicia y Derechos Humanos de la Nación y otros s/amparo, 10/11/2015, Nro. Interno: CSJ 841/2013 (49-S) /CS1. Se recomienda el comentario presente en Rodríguez Mancini (2016).

53 Ley 23551 de Asociaciones Sindicales, BO 22/04/1988.

54 CSJN, Acordada 12/2016, 05/04/2016, AR/LCON/75EC. Además del artículo de Salgado (2016), que será citado un poco más adelante, se recomienda el comentario a la acordada presente en Verbic y Sucunza (2016). 
Así como en 2014 la obligación registral pesaba sobre "el tribunal de radicación de la causa" ${ }^{55}$ la disposición en análisis dispone el deber de acatar las nuevas medidas a "los tribunales y las partes". ${ }^{56}$ Esta intervención de la Corte produce un verdadero cambio de paradigma al generar normas que inciden sobre los derechos procesales de los sujetos que intervienen en juicio.

La regulación más relevante a los efectos del presente estudio se encuentra en el punto II, en el cual se establece que la parte actora debe, "[e]n los términos del artículo 330 del Código Civil y Comercial de la Nación, [...] b) justificar la adecuada representación del colectivo; [e] c) indicar, de corresponder, los datos de la inscripción en el Registro Nacional de Asociaciones de Consumidores; $[\ldots] "$.

Se admite, de esta manera, que no siempre corresponde la inscripción en un registro especial de asociaciones para hallarse legitimado de manera extraordinaria, es decir, solo será exigible en caso de existir uno.

\subsubsection{Asociación Sepa Defenderse (2018) ${ }^{57}$}

Se suscita un conflicto negativo de competencia que, con sus matices, llega a la CSJN, la cual resuelve que resulta inoficioso pronunciarse sobre la cuestión planteada porque la Asociación de Consumidores que promueve el expediente fue excluida del ReNAC durante su tramitación.

A lo reglado en DEFEINDER se le suma una interpretación adicional sobre el tiempo durante el cual la asociación civil debe encontrarse registrada "conforme a la ley". Este recaudo no debe observarse solo al incoar el proceso, sino también durante toda su tramitación.

\subsection{Estándar judicial en materia de legitimación extraordinaria de asociaciones civiles}

Reseñé los aspectos más relevantes de lo actuado por la CSJN a lo largo de casi diez años, desde Halabi en 2009 hasta Asociación Sepa Defenderse en 2018, dos acordadas mediante.

En lo que respecta a la legitimación extraordinaria de asociaciones civiles para intervenir en supuestos de tutela individual homogénea, puedo afirmar

\footnotetext{
55 Ídem, punto 3.

56 Ídem, punto I.

57 CSJN, Asociación Sepa Defenderse c/Secretaría de Energía de la Nación y otros s/amparo colectivo, 26/12/2018, La Ley, AR/JUR/79291/2018.
} 
que el acervo producido por la Corte genera una regla que podría enunciarse del siguiente modo:

La legitimación extraordinaria concedida por el artículo $43 \mathrm{CN}$ a las asociaciones civiles para la tutela de derechos individuales homogéneos en el marco de procesos colectivos se encuentra permitida ("Halabi") y, en cada caso, el juez que interviene debe verificar que a) la asociación sea un adecuado representante del colectivo, al ser su objeto estatutario idóneo a tal fin ("PADEC", "Acordada 32/2014" y "Acordada 12/2016”); b) cuente con la necesaria autorización legal de la autoridad pública competente para funcionar ("DEFEINDER"), no siendo suficiente la mera presentación del trámite para obtenerla ("SUTPLA"); c) contar con una inscripción especial en razón de la materia, en caso de que una ley determine dicha necesidad ("DEFEINDER" y "Acordada 12/2016"); y d) conservar durante todo el proceso los requisitos legales necesarios para incoarlo ("Sepa Defenderse").

\subsection{Facultades legislativas de la CSJN según el propio tribunal}

La propia Corte, en los fallos relativos a la materia, así como en las acordadas comentadas anteriormente, reconoce la imperiosa necesidad del dictado de normas legales para la regulación de los procesos colectivos.

A modo de ejemplo, conviene recordar lo dicho -y ya citado anteriormente- por la CSJN en el considerando 12 de Halabi. De manera paulatina, se fueron generando lineamientos jurisprudenciales que marcaban un norte para la interposición de acciones colectivas y la respuesta de la judicatura ante estas.

El punto cúlmine de esta tarea se alcanzó con el dictado de dos acordadas, en cuyos considerandos se citan tres normas en las que, según la propia CSJN, se le otorgan las atribuciones necesarias para emitir este tipo de disposiciones. A continuación, haré referencia a estas, transcribiendo lo que allí se establece.

En primer lugar, la Ley 48 (1863), que en su artículo 18 indica que "[1]a Corte Suprema podrá establecer los reglamentos necesarios para la ordenada tramitación de los pleitos, con tal que no sean repugnantes a las prescripciones de la Ley de Procedimientos".

Segundo, el artículo 10 de la Ley 4055 (1902) dispone que "[l]a Suprema Corte ejercerá superintendencia sobre las Cámaras Federales, Jueces de Sección, Jueces Letrados de Territorios Nacionales y demás funcionarios de la Justicia Federal, debiendo dictar los reglamentos convenientes para procurar la mejor administración de justicia”.

Tercero, la ley de reforma del Código Procesal Civil y Comercial de la Na- 
ción, obrada por Ley 25488 (2001), que en su artículo 4, párrafo $2^{\circ}$ establece que "[l]a Corte Suprema de Justicia de la Nación queda facultada para dictar las medidas reglamentarias y todas las que considere adecuadas para el mejor cumplimiento de las normas y fines de esta reforma".

En el considerando 10 de la Acordada 12/2016 la Corte menciona que, ante la falta de una norma emanada por el Congreso de la Nación,

resulta indispensable fijar reglas orientadas a ordenar la tramitación de este tipo de procesos a fin de evitar circunstancias que pueden conllevar a situaciones de gravedad institucional, hasta tanto el Poder Legislativo Nacional sancione una ley que regule su procedimiento.

Por tal motivo, la citada norma tiene vigencia hasta este último momento citado, ${ }^{58}$ el cual no ha sucedido hasta ahora.

Sin lugar a dudas, la CSJN reconoce que se encuentra ejerciendo facultades regulatorias exclusivas del legislador, aunque realiza cierto esfuerzo por justificar dicha intromisión. Ante esta situación, Salgado (2016) sostiene que "la omisión imperturbable del Poder Legislativo es lo que legitima, antes que autoriza, a la Corte a avanzar en el desarrollo del proceso colectivo" (p. 4), por lo que "[e]l silencio será un nuevo elemento que legitimará el obrar futuro de la Corte en este campo, avanzando en [su] regulación integral [...]” (p. 5).

En apoyo de este rol legislativo, Azar-Baud (2016) defiende el dictado de este tipo de normativa como herramienta idónea para

vigorizar el rol del juez como un director y/o saneador del proceso colectivo, con amplias facultades y obligaciones, [...] aplicado a un proceso complejo y sensible, donde los paradigmas han cambiado y se vuelve necesario de dotar al proceso civil de características dispositivas mixtas, tomando rasgos del inquisitivo sin perder el eje del dispositivo. (p. 3)

Si bien en esta primera parte del trabajo me encuentro realizando una tarea de índole mayormente descriptiva, quiero adelantar mi desacuerdo con la opinión de ambos autores, sobre el cual me explayaré más adelante.

El camino recorrido por la Corte va por un plano inclinado, de menor a mayor, el cual culmina con el dictado de normas procesales para tramitar procesos colectivos, lo cual perfila así un rol activista en la materia. ${ }^{59}$

58 Cfr. Acordada 12/2016, Punto IV.

59 Cfr. Salgado (2011, pp. 131-141). 


\subsection{Legislación nacional vigente y proyectos normativos}

Luego de lo recorrido, llega el turno de analizar lo que sucede en el plano normativo formal en cuanto a la recepción de las herramientas legales, vigentes y sin haber sido aprobadas aún, para promover supuestos de tutela individual homogénea.

\subsubsection{Código Civil y Comercial de la Nación}

Estas nociones teóricas y sus antecedentes jurisprudenciales han encontrado resistencia para ser incorporadas en la normativa legal vigente.

En la génesis del Código Civil y Comercial de la Nación, su comisión redactora introdujo en el anteproyecto diversas disposiciones, receptando la clasificación de derechos en simplemente individuales, individuales homogéneos y colectivos. El artículo 14 disponía

Derechos individuales y de incidencia colectiva. En este Código se reconocen: a) derechos individuales; b) derechos individuales, que pueden ser ejercidos mediante una acción colectiva, si existe una pluralidad de afectados individuales, con daños comunes pero divisibles o diferenciados, generados por una causa común, según lo dispuesto en el Libro Tercero, Título V, Capítulo 1; c) derechos de incidencia colectiva, que son indivisibles y de uso común. El afectado, el Defensor del Pueblo, las asociaciones registradas y otros sujetos que dispongan leyes especiales, tienen legitimación para el ejercicio de derechos que protegen al ambiente, a la competencia, al usuario y al consumidor, así como a los derechos de incidencia colectiva en general. La ley no ampara el ejercicio abusivo de los derechos individuales cuando puede afectar gravemente al ambiente y a los derechos de incidencia colectiva en general.

Asimismo, la iniciativa incluyó una sección en la cual se creaba un marco regulatorio para los "Daños a los derechos de incidencia colectiva". Allí, entre los artículos 1746 y 1748 se receptaban de manera condensada la doctrina de los precedentes de la CSJN en la materia. ${ }^{60}$

60 "Artículo 1746.- Daño a derechos individuales homogéneos. Hay daños a derechos individuales homogéneos cuando media una pluralidad de damnificados individuales con daños comunes pero divisibles o diferenciados, generados en forma indirecta por la lesión a un derecho colectivo o provenientes de una causa común, fáctica o jurídica. Pueden demandar la reparación de esta clase de daños: a) el afectado individual o agrupado que demuestre un interés propio; b) el Defensor del Pueblo de la Nación, de las provincias y de la Ciudad Autónoma de Buenos Aires, según corresponda; c) las organizaciones no gubernamentales de defensa de intereses colectivos, en los términos del artículo 43 de la Constitución Nacional". 
Finalmente, el proyecto que efectivamente elevó el Poder Ejecutivo al Congreso -el cual dio origen a la norma hoy vigente- no contiene siquiera el término "acción colectiva"; su artículo 14 fue modificado, ${ }^{61}$ eliminando los derechos individuales homogéneos, y la sección mencionada en el párrafo anterior fue suprimida.

Aparentemente, este revés legislativo no generó ningún tipo de cambio en la praxis tribunalicia y la CSJN continuó con la línea jurisprudencial iniciada en Halabi para los supuestos de tutela de intereses individuales homogéneos. ${ }^{62}$ Según la interpretación de Lorenzetti (2017, p. 25), esta supresión no afecta los derechos homogéneos por ser, en esencia, derechos individuales que sí se encuentran expresamente receptados en el nuevo Código. ${ }^{63}$

"Artículo 1747.- Presupuestos de admisibilidad. Para el reconocimiento de la legitimación en los procesos en los que se reclama el resarcimiento de daños a derechos de incidencia colectiva o individuales homogéneos, se debe exigir que el legitimado cuente con aptitudes suficientes para garantizar una adecuada defensa de los intereses colectivos. Entre otros requisitos, el juez debe tener en cuenta: a) la experiencia, antecedentes y solvencia económica del legitimado para la protección de este tipo de intereses; b) la coincidencia entre los intereses de los miembros del grupo, categoría o clase y el objeto de la demanda. Para la admisibilidad de los procesos en los que se reclama la reparación de daños a derechos individuales homogéneos es requisito necesario que el enjuiciamiento concentrado del conflicto constituya una vía más eficiente y funcional que el trámite individual, para lo cual el juez debe tener en consideración aspectos tales como el predominio de las cuestiones comunes sobre las particulares o la imposibilidad o grave dificultad de constituir un litisconsorcio entre los afectados".

"Artículo 1748.- Alcances de la sentencia. Cosa juzgada. En los procesos colectivos referidos a derechos individuales homogéneos, la sentencia hace cosa juzgada y tiene efecto erga omnes, excepto que la acción sea rechazada. Este efecto no alcanza a las acciones individuales fundadas en la misma causa. Si la pretensión colectiva es acogida, los damnificados pueden solicitar la liquidación y la ejecución de la sentencia a título personal ante el juez de su domicilio. La sentencia que rechaza la acción colectiva no impide la posibilidad de promover o continuar las acciones individuales por los perjuicios ocasionados a cada damnificado".

61 "Artículo 14.- Derechos individuales y de incidencia colectiva. En este Código se reconocen: a) derechos individuales; b) derechos de incidencia colectiva. La ley no ampara el ejercicio abusivo de los derechos individuales cuando pueda afectar al ambiente y a los derechos de incidencia colectiva en general".

62 Ver Lorenzetti (2014, p. 75). En la nota al pie No 80, el autor de esta obra, ministro de la Corte Suprema de Justicia de la Nación y protagonista principal en la redacción del anteproyecto del Código Civil y Comercial de la Nación, plantea al pasar y sin dar mayores precisiones que "[e]n el proyecto elaborado por la Comisión se incluía una tercera categoría: b) Derechos individuales, que pueden ser ejercidos mediante una acción colectiva, si existe una pluralidad de afectados individuales, con daños comunes pero divisibles o diferenciados, generados por una causa común, según lo dispuesto en el Libro Tercero, Título V, Capítulo 1, pero ello fue suprimido por el Poder Ejecutivo nacional”.

63 En el mismo sentido, afirma Catalano (2015) que "nada impide que se considere a los intereses individuales homogéneos como integrantes de la categoría de derechos de incidencia colectiva que nombra la norma, junto a los derechos difusos o propiamente colectivos. Esta télesis del art. 14 se revela como la única salida para seguir avanzando en un ámbito que no admite vuelta atrás, so riesgo de quedar a espaldas de la realidad social, donde las cuestiones de discriminación, competencia, 


\subsubsection{Normas legales con alguna referencia a procesos colectivos específicos}

Si bien en el CPCCN la regulación vinculada a la legitimación activa no ha sufrido cambios, sí existen normas procesales de gran importancia para el objeto del presente estudio en diversos ámbitos.

\subsubsection{Derechos de los usuarios y consumidores}

La propia reforma constitucional de 1994, la cual ya fue comentada por su importancia en materia del proceso de amparo, sostuvo el protagonismo que la Ley 24240 les otorgó a las asociaciones de consumidores y usuarios al incorporar el nuevo artículo 42 de la CN. ${ }^{64}$

Al tiempo que la "Ley de Leyes" contiene disposiciones pertinentes, lo propio sucede con normas supraconstitucionales que poseen preceptos procesales para la tutela colectiva de derechos, algunas de las cuales serán detalladas a continuación.

La principal que conviene analizar es la citada Ley de Defensa del Consumidor (en adelante, LCD), en vigencia desde 1993. En sus capítulos XIII y XIV regula la legitimación extraordinaria de un tipo específico de asociaciones civiles, las de usuarios y consumidores.

En el artículo 52 se reconoce entre los legitimados procesales en la defensa de los intereses de usuarios y consumidores a las asociaciones. En lo atinente al presente estudio, dicha cláusula establece

Acciones Judiciales. Sin perjuicio de lo dispuesto en esta ley, el consumidor y usuario podrán iniciar acciones judiciales cuando sus intereses resulten afectados o amenazados.

acceso a la información y defensa de los derechos de usuarios y consumidores, por mencionar las más sobresalientes, se plantean con habitualidad".

64 "Artículo 42.- Los consumidores y usuarios de bienes y servicios tienen derecho, en la relación de consumo, a la protección de su salud, seguridad e intereses económicos; a una información adecuada y veraz; a la libertad de elección, y a condiciones de trato equitativo y digno.

Las autoridades proveerán a la protección de esos derechos, a la educación para el consumo, a la defensa de la competencia contra toda forma de distorsión de los mercados, al control de los monopolios naturales y legales, al de la calidad y eficiencia de los servicios públicos, y a la constitución de asociaciones de consumidores y de usuarios.

La legislación establecerá procedimientos eficaces para la prevención y solución de conflictos, y los marcos regulatorios de los servicios públicos de competencia nacional, previendo la necesaria participación de las asociaciones de consumidores y usuarios y de las provincias interesadas, en los organismos de control”. 
La acción corresponderá al consumidor o usuario por su propio derecho, a las asociaciones de consumidores o usuarios autorizadas en los términos del artículo 56 de esta ley, a la autoridad de aplicación nacional o local, al Defensor del Pueblo y al Ministerio Público Fiscal. Dicho Ministerio, cuando no intervenga en el proceso como parte, actuará obligatoriamente como fiscal de la ley.

En las causas judiciales que tramiten en defensa de intereses de incidencia colectiva, las asociaciones de consumidores y usuarios que lo requieran estarán habilitadas como litisconsortes de cualquiera de los demás legitimados por el presente artículo, previa evaluación del juez competente sobre la legitimación de éstas.

Resolverá si es procedente o no, teniendo en cuenta si existe su respectiva acreditación para tal fin de acuerdo a la normativa vigente [...].

El Decreto Reglamentario admite que esta posibilidad de accionar en cabeza de una asociación de consumidores no necesita de ningún tipo de reconocimiento por parte del particular afectado o titular de la relación jurídica sustancial (el usuario o consumidor individual) en caso de que se esté promoviendo la protección de algún interés general.

Más adelante, el artículo 55 reconoce de manera más clara dicha legitimación, supeditada a la obtención de la correspondiente autorización para funcionar por parte de la autoridad pública competente en la materia

Legitimación. Las asociaciones de consumidores y usuarios constituidas como personas jurídicas reconocidas por la autoridad de aplicación, están legitimadas para accionar cuando resulten objetivamente afectados o amenazados intereses de los consumidores o usuarios, sin perjuicio de la intervención de éstos prevista en el segundo párrafo del artículo 58 de esta ley.

Las acciones judiciales iniciadas en defensa de intereses de incidencia colectiva cuentan con el beneficio de justicia gratuita.

Los requisitos para obtener dicho reconocimiento se encuentran en los artículos 56 y 57 de la ley, en su Decreto Reglamentario 1798/1994 y en las resoluciones y disposiciones que norman el ReNAC.

Esta normativa regula la legitimación extraordinaria colectiva de las asociaciones de usuarios y consumidores, pero lo más importante es que define los 
alcances de dicha intervención procesal en el artículo $54^{65}$ desde la reforma introducida en 2008 por la Ley 26361. ${ }^{66}$

A pesar de existir algunas nociones que dan un marco general en la normativa para el desarrollo de procesos de tutela individual homogénea en materia de usuarios y consumidores, Picasso y Vázquez (2013) afirman que

la disposición en análisis despeja toda duda en cuanto a la existencia de acciones colectivas en la materia, regulando algunos aspectos de particular relevancia en este tipo de procesos. Sin perjuicio de ello, no debe dejar de señalarse que esta norma no constituye un procedimiento completo y acabado en la materia, sino que se refiere a algunos aspectos de las acciones colectivas, a saber: a) el procedimiento para arribar a un acuerdo o transacción y sus efectos; b) el alcance de la cosa juzgada en este tipo de litigios; y c) el procedimiento para la determinación de la indemnización que corresponda a cada uno de los consumidores, en caso de que el juicio tenga contenido patrimonial. (p. 676)

Como puede percibirse, existe una diferencia sustancial entre el desarrollo jurisprudencial de la tutela individual homogénea y la que ofrecen los derechos de los usuarios y consumidores, al existir en este último caso normas procesales con algún grado de mayor especificidad.

65 "Articulo 54.- Acciones de incidencia colectiva. Para arribar a un acuerdo conciliatorio o transacción, deberá correrse vista previa al Ministerio Público Fiscal, salvo que éste sea el propio actor de la acción de incidencia colectiva, con el objeto de que se expida respecto de la adecuada consideración de los intereses de los consumidores o usuarios afectados. La homologación requerirá de auto fundado. El acuerdo deberá dejar a salvo la posibilidad de que los consumidores o usuarios individuales que así lo deseen puedan apartarse de la solución general adoptada para el caso.

La sentencia que haga lugar a la pretensión hará cosa juzgada para el demandado y para todos los consumidores o usuarios que se encuentren en similares condiciones, excepto de aquellos que manifiesten su voluntad en contrario previo a la sentencia en los términos y condiciones que el magistrado disponga.

Si la cuestión tuviese contenido patrimonial establecerá las pautas para la reparación económica o el procedimiento para su determinación sobre la base del principio de reparación integral. Si se trata de la restitución de sumas de dinero se hará por los mismos medios que fueron percibidas; de no ser ello posible, mediante sistemas que permitan que los afectados puedan acceder a la reparación y, si no pudieran ser individualizados, el juez fijará la manera en que el resarcimiento sea instrumentado, en la forma que más beneficie al grupo afectado. Si se trata de daños diferenciados para cada consumidor o usuario, de ser factible se establecerán grupos o clases de cada uno de ellos y, por vía incidental, podrán éstos estimar y demandar la indemnización particular que les corresponda”.

Ley 26361, BO 07/04/2008. 


\subsubsection{Asociaciones sindicales}

Especial y breve mención merece la Ley de Asociaciones Sindicales, previa a la última reforma constitucional argentina del siglo XX. En ella se otorga de manera genérica a los gremios la legitimación para "[d]efender y representar ante el Estado y los empleadores los intereses individuales y colectivos de los trabajadores". ${ }^{67}$

Esta norma concede dicha posibilidad siempre que la entidad obtenga la inscripción con personería gremial prevista en los artículos 25 y siguientes de la ley. ${ }^{68}$

Asimismo, a diferencia de lo que podría suceder con la LDC, existe más bien un reconocimiento con escasas precisiones procesales para la tutela individual homogénea de los derechos de los trabajadores.

\subsubsection{Propuestas normativas}

Lo sostenido por la CSJN en el considerando 9 de Halabi, ya mencionado previamente, tuvo su eco en la labor legislativa de integrantes de ambas cámaras del Honorable Congreso de la Nación, ${ }^{69}$ sin haber obtenido resultados exitosos hasta ahora.

Asimismo, el 22 de diciembre de 2017, el Poder Ejecutivo Nacional hizo públicas sus intenciones de emplear sus facultades para presentar iniciativas legislativas a tratar por el Poder Legislativo. Así fue cómo el Ministerio de Justicia y Derechos Humanos de la Nación creó la Comisión Redactora del Anteproyecto de Ley de Procesos Colectivos en el ámbito del programa Justicia 2020, ${ }^{70}$ a la cual le encomendó "desarrollar un marco normativo que ordene el tratamiento de las cuestiones de afectación masiva a través de reglas que aporten a los justiciables accesibilidad, previsibilidad, coherencia en las decisiones y eficacia en el cumplimiento de los decisorios". ${ }^{71}$

Si bien el trabajo no concluyó de manera definitiva, se hizo público un borrador en la página web del Ministerio de Justicia y Derechos Humanos en mayo de 2018, ${ }^{72}$ el cual fue ampliamente comentado y valorado por la más

\section{Artículo 31, inciso a).}

68 Cfr. Salgado (2011, p. 168).

69 Pueden encontrarse numerables referencias a los proyectos de ley presentados en Dirección de Servicios Legislativos del Honorable Congreso de la Nación (2019, pp. 3-4).

70 Cfr. Resolución del Ministerio de Justicia y Derechos Humanos de la Nación (2017).

71 Ídem.

72 El link en el cual fue publicado (https://www.argentina.gob.ar/justicia/foro/topic/ley-de-proce- 
destacada doctrina especializada en la materia. ${ }^{73}$ Sin embargo, nunca vio oficialmente la luz ni discurrió el trámite legislativo ordinario.

Vale la pena también tener siempre presente, como referencia internacionalmente conocida, el Código Modelo de Procesos Colectivos para Iberoamérica, elaborado por el Instituto Iberoamericano de Derecho Procesal ${ }^{74}$ y publicado en el año 2004. ${ }^{75}$

\section{Síntesis parcial}

Hace poco más de diez años, la Corte comenzó a recorrer un camino en el cual otorgó legitimación extraordinaria de las asociaciones civiles en los supuestos de tutela individual homogénea. Luego de lo descripto a lo largo de los apartados anteriores, en este procuraré realizar en pocas líneas una valoración global del mencionado proceso en la praxis de la justicia nacional y federal.

La CSJN procuró impulsar la visión tripartita de los derechos -simplemente individuales, colectivos e individuales homogéneos- receptada desde el Código Modelo de Procesos Colectivos para Iberoamérica. A pesar del esfuerzo realizado, no logró permear en la legislación formal vigente y sufrió un duro revés al aprobarse el Código Civil y Comercial de la Nación, en el cual se suprimió la triple categorización antes mencionada.

Esta circunstancia no se constituyó en un obstáculo para que la Corte realizara el amplio desarrollo descripto durante esta sección que aquí concluyo. Si bien es cierto que contó con la vaga referencia presente en el artículo 43 de la $\mathrm{CN}$ a los derechos de incidencia colectiva, una pretendida operatividad de la legitimación extraordinaria en favor de las asociaciones civiles allí mencionada y alguna normativa infraconstitucional, la realidad es que careció de "pautas adjetivas mínimas que regulen la materia”, como ella misma reconoció en el ya citado considerando 20 de Halabi.

Al abrir la puerta de la tutela individual homogénea en 2009, creó de mane-

sos-colectivos) ya no se encuentra activo para su consulta.

73 Entre ellos, Camps (2019); Catalano (2018); Giannini (2018); Halabi y Díaz Cisneros (2019); Verbic (2018); entre otros.

74 Según la presentación institucional que figura en su página web, "[e]l Instituto Iberoamericano de Derecho Procesal se fundó en Montevideo, en las Primeras Jornadas Latinoamericanas de Derecho Procesal, realizadas en 1957, en homenaje a la Memoria de Eduardo J. Couture. [...] El Ministerio de Relaciones Exteriores de la República Oriental del Uruguay resolvió en el 2010 otorgarle personería jurídica" (http://www.iibdp.org/es/presentacion-institucional/).

75 Ver el resumen explicativo del Código Modelo en Lorenzetti (2017, pp. 118-121). 
ra paulatina un marco propicio para que una nueva clase de expedientes judiciales proliferara. Con casos de los más variados, la Corte encontró un campo fértil para elaborar un acervo jurisprudencial que terminó de adquirir un verdadero carácter vinculante con el dictado de las Acordadas 32/2014 y 12/2016.

El aparente vacío legislativo en la materia fue el espacio que la CSJN se propuso ocupar y lo hizo generando verdaderas normas procedimentales con un impacto contundente en los procesos civiles de la justicia nacional y federal de nuestro país.

De esta manera, con un impulso en solitario por parte de la Corte como cabeza del Poder Judicial de la Nación, las asociaciones civiles lograron adquirir un poder del que carecían hasta el momento: el de la legitimación extraordinaria en acciones de clase, a través del cual pueden constituirse en parte actora pretendiendo la defensa de derechos enteramente individuales y ajenos en un proceso judicial.

\section{Los alcances de la facultad reglamentaria de la CSJN}

En la primera parte, desarrollé el modo en el cual la Corte generó un nuevo camino procesal y focalicé la atención del presente estudio en la legitimación extraordinaria reconocida para asociaciones civiles en supuestos de tutela individual homogénea.

Al tiempo que la sección anterior fue de índole mayormente descriptiva, en esta etapa procuraré realizar un análisis crítico sobre el obrar de la CSJN a la luz de las cláusulas normativas vigentes.

\subsection{Límites constitucionales, convencionales y legales}

\subsubsection{La garantía del debido proceso y el derecho de instar ante las autoridades} Indica el artículo 18 de la $\mathrm{CN}$ :

Ningún habitante de la Nación puede ser penado sin juicio previo fundado en ley anterior al hecho del proceso, ni juzgado por comisiones especiales, o sacado de los jueces designados por la ley antes del hecho de la causa. [...] Es inviolable la defensa en juicio de la persona y de los derechos [...].

Una lectura cuidadosa de esta norma vinculada al derecho de petición plasmado en el artículo 14 de la $\mathrm{CN}$ permite sostener que dichas cláusulas habilitan a las partes procesales a exigir que los órganos judiciales intervinientes se ciñan 
a las normas sustantivas y adjetivas vigentes al momento del hecho que genera la disputa puesta a consideración de estos últimos.

Si bien podría afirmarse que la redacción de la citada disposición extiende una garantía únicamente para los procesos de índole penal, resulta sumamente iluminador el artículo 8, inciso 1 de la Convención Americana sobre Derechos Humanos, con jerarquía constitucional en la Argentina en virtud del artículo 75 , inciso 22, párrafo 2 . De allí se infiere que la garantía del debido proceso es aplicable en favor de toda persona "para la determinación de sus derechos y obligaciones de orden civil, laboral, fiscal o de cualquier otro carácter” . 76 Por lo tanto, rige ante la tramitación de todo expediente jurisdiccional en cualquier materia. $^{77}$

Por su parte, el artículo 14 de la $\mathrm{CN}$ reconoce el derecho de peticionar ante las autoridades "conforme a las leyes que reglamenten su ejercicio". La acción procesal a través de la instancia judicial es una de las formas posibles de ejercer esta facultad ${ }^{78}$ y esta se debe regir por las pautas legales que norman el proceso.

Para algunas materias específicas, la propia Constitución Nacional prevé expresamente la necesidad de una regulación legal de los procesos. Así lo establece, por ejemplo, el artículo 42 de la $\mathrm{CN}$ para los casos de derechos de los consumidores y usuarios:

[...] La legislación establecerá procedimientos eficaces para la prevención y solución de conflictos, y los marcos regulatorios de los servicios públicos de competencia nacional, previendo la necesaria participación de las asociaciones de consumidores y usuarios y de las provincias interesadas, en los organismos de control.

76 En similar sentido, ver artículo 14, inciso 1 del Pacto Internacional de Derechos Civiles y Políticos.

77 Así lo reconoce la Corte Interamericana de Derechos Humanos, por ejemplo, en su precedente Pollo Rivera y otros vs. Perú, sentencia del 21 de octubre de 2016 (fondo, reparaciones y costas). Allí, en su párrafo 209, el mencionado organismo internacional sostiene: "Este Tribunal ha señalado que la aplicación de las garantías contenidas en el artículo 8 de la Convención Americana, si bien se titula 'Garantías Judiciales', no se limita a los recursos judiciales en sentido estricto, sino al conjunto de requisitos que deben observarse en las instancias procesales a efectos de que las personas estén en condiciones de defender adecuadamente sus derechos ante cualquier tipo de acto del Estado que pueda afectarlos. Es decir, cualquier actuación u omisión de los órganos estatales dentro de un proceso, sea administrativo sancionatorio o jurisdiccional, debe respetar el debido proceso legal. Además, de acuerdo a lo dispuesto en el artículo 8.1 de la Convención, es claro que, en la determinación de los derechos y obligaciones de las personas, de orden penal, civil, laboral, fiscal o de cualquier otro carácter, se deben observar 'las debidas garantías' que aseguren, según el procedimiento de que se trate, el derecho al debido proceso".

78 En este sentido, ver lo explicado en Alvarado Velloso (2009, pp. 55-66); Briseño Sierra (como se citó en Calvinho, 2013, p. 21); Couture (2010 [1948], pp. 9-26). 
Nunca está de más recordar que esta garantía de legalidad, exigida para la regulación de los derechos constitucionales, requiere que las normas dictadas provengan del poder legislativo y cumplan con los requisitos que los ordenamientos jurídicos prevén para su entrada en vigencia (promulgación, publicación, entre otros), o, al menos y de manera excepcional, surjan de los procesos de delegación legislativa expresamente presentes en la normativa constitucional interna. ${ }^{79}$

Por lo tanto, nuestra Constitución y los tratados internacionales con jerarquía constitucional imponen la obligación de que no cualquier norma ni órgano estatal regulen los derechos de las partes procesales, sino solo los que han recibido de manera expresa la atribución de dictar leyes en sentido formal.

\subsubsection{Reglamentos y acordadas del Poder Judicial de la Nación}

Resulta de vital importancia detenerse en una facultad normativa otorgada por la propia Constitución Nacional a la Corte. Me refiero a la atribución que se le reconoce para dictar su reglamento interior en el artículo $113,{ }^{80}$ sin conceder allí ningún tipo de atribución para generar normas que puedan incidir regulando los derechos de los particulares en el marco de un proceso judicial, lo cual es materia reservada a los poderes legislativos, como ya expliqué anteriormente.

Es una potestad que puede compararse a la que detentan las cabezas de los otros poderes del Estado. Por un lado, la del Poder Ejecutivo Nacional de dictar decretos autónomos, contemplada en el artículo 99, inciso 1 de la $\mathrm{CN},{ }^{81} \mathrm{y}$, por el otro, con la de cada cámara del Honorable Congreso de la Nación de dictar su propio reglamento, prevista en el artículo 66 de la $\mathrm{CN} .{ }^{82}$

Sobre este punto, sostiene Sacristán (2020):

el artículo 113 coloca directamente en cabeza de la Corte Suprema -por "delegación” del Constituyente, si se quiere, o, mejor dicho, por "creación” de este- una competencia reglamentaria de fuente textual constitucional enderezada primigeniamente al plano intrapoder, internamente interorgánico, sin perjuicio de eventuales efectos o beneficios hacia terceros. (pp. 512-513)

79 Ver lo dicho por la Corte Interamericana de Derechos Humanos en Opinión Consultiva OC-6/86. La expresión "leyes" en el artículo 30 de la Convención Americana sobre Derechos Humanos. Solicitada por el Gobierno de la República Oriental del Uruguay, 09/05/1986.

80 "Artículo 113: La Corte Suprema dictará su reglamento interior y nombrará a sus empleados".

81 Cfr. Sacristán (2020, pp. 499-530 y 502-510).

82 Cfr. Gelli (2018b, p. 567). 
Respecto a las disposiciones legales en análisis, explica Salgado (2016, p. 4): "Las facultades conferidas son aquellas inherentes a todo poder público para su existencia y conservación, recursos propios para mantener y hacer práctica su autoridad, y toda la independencia necesaria para su organización interna”.

Por lo tanto, según el mismo autor, las normas que dicte la Corte en consecuencia poseen la virtualidad de ser

reglamentarias a efectos del mejoramiento del servicio de justicia, mas siempre están supeditadas a las leyes procesales y, obviamente, al bloque de constitucionalidad. Indefectiblemente su alcance ha quedado delimitado a las previsiones del art. $113 \mathrm{CN}$, que faculta a la Corte a dictar "su reglamento interior" lo que implica su organización, gobierno y funcionamiento. Salgado $(2016, \text { p. } 4)^{83}$

No solo la Constitución Nacional le reconoce cierta facultad regulatoria a la Corte Suprema. Sobre este punto conviene detenerse en el análisis de las tres normas de rango legal citadas ${ }^{84}$ por la CSJN en los considerandos de algunas de sus acordadas ${ }^{85}$ como fundamento de la atribución para el dictado de estas. Palacio (2017) explica
A fin de facilitar el mejor funcionamiento de la administración de justicia, y frente a la imposibilidad de prever los múltiples problemas de orden práctico que la actividad procesal puede suscitar, las leyes suelen conferir a los órganos judiciales superiores la facultad de dictar normas generales, destinadas a com- plementar o integrar los textos legales relativos a determinados aspectos de la organización judicial y a la regulación de los procedimientos. (§ 30)

Asimismo, sobre esta atribución reglamentaria reconoce claros límites para su ejercicio y sostiene que posee "una limitación sustancialmente análoga a la que el art. 99 inc. $2^{\circ} \mathrm{CN}$ impone al Poder Ejecutivo en lo que respecta a la reglamentación de las leyes nacionales" (\$33).

Para Sacristán (2020, p. 522), la actividad reglamentaria de la CSJN puede ser más amplia respetando siempre una serie de límites, entre los que se

83 Cabe destacar que el autor que realiza esta consideración sostiene la necesidad de contar con una ley que regule los supuestos de tutela individual homogénea -sobre todo ante la necesidad de clarificar cuestiones no tratadas-, pero no descalifica el proceder de la CSJN.

84 Fueron mencionadas en la primera parte del trabajo las leyes 48 (1863), 4055 (1902) y 25488 (2001).

85 Las pioneras fueron la Acordada 28/2004, de autorización de Amigos del Tribunal, y la Acordada 4/2007, del reglamento sobre los escritos de interposición de los recursos extraordinarios y de queja. Esta misma línea argumentativa fue seguida por las acordadas 32/2014 y 12/2016. 
destacan no invadir materias reservadas al Poder Legislativo y no contrariar la legislación vigente.

De cualquier manera, puedo sostener que no existe disposición normativa alguna que habilite a la Corte a dictar legislación general que regule los derechos de las partes en el marco de un proceso.

\subsubsection{Delegación legislativa}

En las diversas acordadas en las que la Corte actúa ejerciendo facultades exclusivas del legislador, da a entender que es el propio Congreso de la Nación el que ha obrado una especie de delegación legislativa de dichas atribuciones en cabeza del Poder Judicial. Sin embargo, esa posibilidad regulada en el artículo 76 de la CN solo se admite entre el Poder Legislativo y el Poder Ejecutivo, según lo establecido por la mencionada norma incorporada en el año 1994

Se prohíbe la delegación legislativa en el Poder Ejecutivo, salvo en materias determinadas de administración o de emergencia pública, con plazo fijado para su ejercicio y dentro de las bases de la delegación que el Congreso establezca [...].

Sagüés (2018) sostiene que admitir una delegación legislativa en cabeza de un órgano judicial resulta improcedente de acuerdo con la regulación actual de dicha figura

si se tiene en cuenta que la Constitución Nacional no la menciona (con lo que podría entenderse que no la autoriza, atento el principio de corrección funcional), y que la reforma de 1994 restringió la delegación legislativa sobre el Poder Ejecutivo, en el nuevo art. 76. (pto. IV)

No solo resulta inviable esta alternativa debido a los argumentos que expone este autor, sino también porque la propia Ley $26122^{86}$ solo regula el trámite de las normas emanadas del Poder Ejecutivo Nacional en virtud de un supuesto de delegación por parte del Congreso.

Por lo tanto, si bien es cierto que el Legislativo facultó al Judicial con ciertas atribuciones reglamentarias, lo hizo solo para materias determinadas y específicas sin permitirle innovar respecto a la legislación procesal ni regular los

86 Ley 26122 de régimen legal de los decretos de necesidad y urgencia, de delegación legislativa y de promulgación parcial de leyes, BO 28/07/2006. 
derechos de las partes en un litigio, lo cual no está expresamente habilitado por la Constitución Nacional.

\section{Tutela individual homogénea: inconsistencias con el ordenamiento jurídico argentino}

A continuación, expondré cuáles son los puntos de la normativa vigente cuya aplicación se pone en crisis por la Corte en los supuestos de tutela individual homogénea promovidos por asociaciones civiles.

\subsection{Legitimación extraordinaria regulada por un órgano incompetente}

En los casos relevados en este trabajo, las asociaciones civiles se presentan en juicio en defensa de un derecho del cual no son titulares, como ya se explicó anteriormente. Así lo admitió la Corte en su acervo jurisprudencial y, de manera más concreta, en sus acordadas 32/2014 y 12/2016.

Específicamente, en el Reglamento de Registro Público de Procesos Colectivos (Acordada 32/2014), lo dicho en el párrafo anterior se concreta en el punto 3 de la norma al atribuirle facultades al órgano judicial que interviene, mediante las que "reconoce la idoneidad del representante y establece el procedimiento para garantizar la adecuada notificación de todas aquellas personas que pudieran tener un interés en el resultado del litigio".

Por su parte, el Reglamento de Actuación en Procesos Colectivos (Acordada 12/2016) le impone al actor la obligación de "justificar la adecuada representación del colectivo" al presentar la demanda.

Sin embargo, este accionar es inconstitucional porque el Poder Judicial de la Nación no cuenta con las atribuciones suficientes para modificar o crear normas procesales que incidan de manera directa en los derechos de las partes procesales, siendo esta una facultad propia del Honorable Congreso de la Nación que, excepcionalmente, puede ser ejercida por el Poder Ejecutivo.

\subsection{Modificación de los requisitos para interponer una demanda}

En el punto II de la Acordada 12/2016, la CSJN expresamente amplía los requisitos para la interposición de una demanda, previstos en el artículo 330 del CPCCN, ${ }^{87}$ circunstancia que ya fue expuesta al comentar el reglamento dictado por la Corte.

87 Ley 17454 de Código Procesal Civil y Comercial de la Nación, BO 07/11/1967. 


\begin{abstract}
Al explicar Palacio (2017) cuál es el alcance de las normas de alcance general dictadas por el alto tribunal, expresa:
\end{abstract}

los reglamentos judiciales no pueden alterar y menos contrariar los requisitos de lugar, tiempo y forma que las leyes imponen a los actos procesales, debiendo limitarse a regular los aspectos secundarios o estrictamente materiales de tales requisitos. No cabría, así, por vía reglamentaria, imponer al actor la carga de incluir, en el escrito de demanda, enunciaciones que hagan al fondo de ésta y no se encuentren contempladas por el art. 330 del Código Procesal de la Nación ni tampoco suprimir alguno de los requisitos exigidos por dicha norma. Pero el reglamento puede exigir, v.gr., que en el escrito respectivo se utilice exclusivamente tinta negra o que los abogados y procuradores que lo suscriben indiquen el tomo y el folio o el número de la matrícula de su inscripción. (\$ 33)

Por lo tanto, si bien la Corte cuenta con cierto poder reglamentario, excede en este caso los límites previstos para su correcto empleo.

\title{
6.3. Tercero interesado \\ El artículo 90 del CPCCN habilita a cualquier persona a
}

intervenir en un juicio pendiente en calidad de parte, cualquiera fuere la etapa o la instancia en que éste se encontrare, quien: 1) Acredite sumariamente que la sentencia pudiere afectar su interés propio. 2) Según las normas del derecho sustancial, hubiese estado legitimado para demandar o ser demandado en el juicio.

Por su parte, el artículo 91 del CPCCN indica:

En el caso del inciso 1. del artículo anterior, la actuación del interviniente será accesoria y subordinada a la de la parte a quien apoyare, no pudiendo alegar ni probar lo que estuviese prohibido a ésta.

En el caso del inciso 2. del mismo artículo, el interviniente actuará como litisconsorte de la parte principal y tendrá sus mismas facultades procesales.

\section{Explica Palacio (2017):}

La intervención de terceros tiene lugar cuando, durante el desarrollo del proceso, y sea en forma espontánea o provocada, se incorporan a él personas distintas a las partes originarias con el objeto de hacer valer derechos o intereses propios, aunque vinculados a la causa o al objeto de la pretensión. (§ 338) 
Resulta paradójico que, al tiempo de que los contornos impuestos por la CSJN a la tutela individual homogénea abren una puerta a las asociaciones civiles -sin contar con recaudos legales claros-, se ha negado la posibilidad de participar en un proceso ya iniciado a sujetos que sí sostienen ser titulares del derecho en disputa, a pesar de lo dispuesto en el inciso $2^{\circ 88}$ de la norma procesal citada en el párrafo anterior.

Así sucedió, por ejemplo, en un expediente que arribó a la Corte mediante recurso de queja, el cual fue resuelto en diciembre de $2014 .{ }^{89}$

En la causa, el alto tribunal negó la procedencia de la solicitud de un grupo de 2641 personas que procuraban adquirir la calidad de parte actora junto con las 25 que habían dado inicio a un proceso vinculado con la prestación de un servicio público domiciliario, entre las que se encontraba representada la Asociación Todos por el Agua. Sorprendentemente, a pesar de no admitirlos como demandantes, mantuvo vigente para ellos la medida cautelar dictada en favor del conjunto más pequeño con anterioridad a su intervención.

La Corte sostuvo que la jurisdicción provincial no estaba respetando los parámetros por ella delineados para los procesos colectivos al darles participación a todos los integrantes de un colectivo que ya se encontraba representado por quienes propiciaron la acción judicial, en especial la asociación civil antes mencionada, la cual, incluso, había celebrado un acuerdo transaccional con la contraparte para darle solución al pleito.

Esta decisión pone de relieve cómo se violentan los derechos procesales previstos en los artículos 90 y 91 del CPCCN, pero se intenta enmendar el error admitiendo la extensión de una tutela cautelar a un conjunto de individuos que no revisten la calidad de parte en el litigio. Quizás, de este modo, la lesión a la garantía del debido proceso no resulta ser tan obvia por sus efectos para

88 Allí se regula la denominada por la doctrina como "intervención adhesiva autónoma o litisconsorcial”. Palacio (2017, §344) sostiene que, en ella, "el ingreso del tercero en el proceso pendiente tiene por objeto hacer valer un derecho propio frente a alguna de las partes originarias, adhiriendo a la calidad (actora o demandada) asumida por la otra u otras".

89 CSJN, Kersich, Juan Gabriel y otros c/Aguas Bonaerenses S.A. y otros s/amparo, 02/12/2014, Nro. Interno: CSJ 42/2013 (49-K). Cabe aclarar que las normas procesales aplicadas en este expediente fueron las que rigen en el territorio de la provincia de Buenos Aires que, en cuanto al instituto de la intervención de terceros, resulta idéntica al CPCCN. Asimismo, la Corte entendió que se encontraba frente a un caso de protección de uno de los componentes del bien colectivo ambiente, el agua potable, sin visualizar que la pretensión se enfocaba claramente en un típico supuesto de tutela individual homogénea, como lo es la provisión del servicio público domiciliario de agua potable. Sin embargo, como bien surge del considerando 9 del fallo, la Corte sostiene que las reglas que deben aplicarse en un proceso colectivo son las que surgen del artículo 43 y de las pautas previstas en su 
con los actores excluidos, pero no puede afirmarse lo mismo para con la parte demandada.

Desde la entrada en vigencia de la Acordada 12/2016, esta virtual desaparición de la figura del tercero interesado quedó plasmada de manera implícita. Al resolver el juez la inscripción de un proceso de estas características, queda identificada la composición del colectivo ${ }^{90}$ y se deben "determinar los medios más idóneos para hacer saber a los demás integrantes del colectivo la existencia del proceso, a fin de asegurar la adecuada defensa de sus intereses". ${ }^{91}$

Sin embargo, según el Reglamento, la promoción de la acción compete solo a quien presente la demanda y justifique su calidad de representante adecuado. Por lo que si el juez arriba a la conclusión de que debe registrar el proceso, ninguno de los integrantes del colectivo representado podrá adquirir la calidad de parte, como sí ocurriría en un proceso tradicional con cualquier tercero interesado admitido en función de la normativa vigente del Código Procesal Civil y Comercial de la Nación.

Este resultado insólito al que arriba la Corte parece contrario a la lógica de otros casos previstos en el derecho vigente, en los que existe algún tipo de legitimación extraordinaria.

Solo a modo de ejemplo habré de referirme al supuesto de nulidad absoluta de un matrimonio y a los sujetos que se hayan habilitado para impulsar el proceso. En el artículo 424 del CCCN se reconoce esta facultad a los cónyuges y también se legitima de manera extraordinaria a las mismas personas que podrían haberse opuesto a la celebración de las nupcias. Resultaría sumamente ilógico y contrario a las normas vigentes que, luego de presentada la demanda por cualquiera de las personas mencionadas en el artículo $411 \mathrm{CCCN}$, se rechazara la participación de cualquiera de los cónyuges que desea intervenir en calidad de parte.

\subsection{Representación procesal: ¿adecuada?}

Si bien la participación prevista por la Constitución Nacional para las asociaciones civiles en supuestos de tutela individual homogénea es en calidad de legitimadas extraordinarias, tanto la doctrina como la jurisprudencia de la CSJN

propia jurisprudencia.

90 Cfr. Reglamento de Actuación en Procesos Colectivos, puntos V.1 y VIII.1.

91 Ídem, punto VIII.2. 
emplean una terminología que puede generar cierta confusión con el instituto de la representación procesal.

Tanto la Acordada 32/2014 como la 12/2016 se refieren a que quien acciona debe ser representante idóneo o adecuado del colectivo involucrado en un caso, sin aportar mayores precisiones respecto a los requisitos o cualidades que permiten adjetivar de esta manera a quien presenta la demanda, dejando más bien el análisis en la apreciación discresional del órgano judicial interviniente.

La discusión respecto a qué se entiende por "representación adecuada" es ajena al objeto del presente estudio, sin perjuicio de que el concepto es relevante en el marco de los procesos de tutela individual homogénea.

Según Gozaíni (2018),

Cada cual tiene una mirada distinta. Algunos quieren proteger los derechos sin mirar quién los representa; otros abren la puerta cuando la "clase" que se presenta tiene un portavoz adecuado; también están los que piden condiciones institucionales de organización y respaldo para actuar en un proceso colectivo, y obran asimismo en este cuadro, superficial y ejemplificativo, los que usan criterios espejados con la representación convencional en los que la protección se dispensa siempre y cuando el representado haya acordado al representante una expresa voluntad de delegación. (pp. 683-684) 92 $^{92}$

Quizás por su similitud terminológica y utilización que suele recibir, conviene hacer un breve repaso sobre el concepto de "representación procesal". Afirma Alvarado Velloso (2009) que

el representante debe acreditar cabalmente su calidad de tal a fin de que el proceso pueda desarrollarse con el objeto de lograr la eficaz heterocomposición del litigio. Si esto no ocurre, la parte contraria puede exigir la vigencia del requisito de marras mediante la excepción de falta de personería y, aún más, debe ser suplible de oficio por el juez (o el árbitro) en razón de que si no se comprueba adecuadamente la representación cuya existencia se afirma, la sentencia que se dicte como culminación del proceso será inútil pues no resultará vinculante para la parte procesal cuya representación no se acreditó. (pp. 581-582)

Si en lugar de un supuesto de legitimación extraordinaria la tutela individual homogénea fuera ejercida mediante el instituto de la representación pro-

92 Esta figura es también analizada de manera exhaustiva en la obra de Gozaíni (2018, pp. 725 y 799 ). Al hablar de la importancia de este concepto, explica Salgado (2011, pp. 211-212) que: "Una vez superado el escalafón de la legitimación extraordinaria, y establecidos los sujetos que se encuentran 
cesal, la representación adecuada se acreditaría cumpliendo con lo dispuesto en los artículos 46 y 47 del CPCCN, que establecen

\begin{abstract}
Artículo 46.- La persona que se presente en juicio por un derecho que no sea propio, aunque le competa ejercerlo en virtud de una representación legal, deberá acompañar con su primer escrito los documentos que acrediten el carácter que inviste [...].
\end{abstract}

Artículo 47.- Los procuradores o apoderados acreditarán su personalidad desde la primera gestión que hagan en nombre de sus poderdantes, con la pertinente escritura de poder [...].

En consonancia con lo ya mencionado, las asociaciones civiles carecen de una representación legal otorgada de manera clara y precisa y, en los casos reseñados, tampoco cuentan con un poder extendido por los verdaderos titulares de los derechos litigiosos.

Ante lo expuesto, podría plantearse en estos supuestos de tutela individual homogénea la excepción prevista en el inciso 2 del artículo 347 del CPCCN, en el que se indica que "[s]ólo se admitirán como previas las siguientes excepciones: [...] 2) Falta de personería en el demandante, en el demandado o sus representantes, por carecer de capacidad civil para estar en juicio o de representación suficiente [...]."

Afirmar lo contrario implicaría admitir que una entidad sin representación

autorizados legalmente para poder estar en el proceso en nombre de la clase y obtener así la tutela de sus derechos [...], la representación adecuada viene a resolver un problema central: la situación de los miembros de la clase ausentes del litigio y el respeto de su garantía a un debido proceso.

Es decir, ¿cómo garantizaremos la inviolabilidad de los derechos de aquellas personas que, sin haber comparecido personalmente al litigio, podrán verse afectadas por la sentencia de mérito que se dicte en él?

El esquema de razonamiento para dar respuesta a esos interrogantes es el siguiente: debe controlarse que aquel que se designe como legitimado extraordinario, a efectos de instar una tutela colectiva, se encuentre en condiciones de defender o gestionar los intereses de todos los miembros ausentes de la clase, tal y como si aquéllos hubieran estado presentes en el litigio, o que su actuación permita afirmar que, de haber ejercido éstos -los ausentes- su defensa de modo personal, no podrían haberlo hecho de una menor manera que su representante.

De esa suerte, si ello ocurre, todos los integrantes de la clase, notificados o no, presentes o ausentes, podrán verse vinculados por la eficacia de la cosa juzgada de ese proceso. Por ello se ha dicho que legitimación y representación adecuada se encuentran en una relación simbiótica.

Se trata de un prerrequisito que debería ser exigido en resguardo del debido proceso en todo litigio colectivo, sin el cual se corre el riesgo de fracasar y recorrer el camino del proceso sin lograr utilidad ninguna a su término. Los elementos a evaluar son que el representante pueda ejercer una tutela vigorosa de los derechos de los miembros ausentes y que no existan intereses contrapuestos con los integrantes del grupo". 
suficiente ejerce la defensa de derechos que no le son propios. Incluso, cabría preguntarse si reconocerles esta participación a las asociaciones civiles contrariando la normativa procesal haría también extensiva las obligaciones y responsabilidades previstas entre los artículos $49^{93}$ y $52^{94}$ del CPCCN.

\section{Síntesis parcial}

Al finalizar esta segunda parte, pude comprobar que la Corte cuenta con atribuciones para el dictado de normas conferidas por la propia Constitución Nacional o por leyes dictadas por el Congreso, cuyo límite está dado por las materias concretas contempladas al otorgar dicha facultad y por los derechos de las partes procesales, que solo pueden ser regulados por una ley formal.

Asimismo, y a la luz de lo expresado en el párrafo anterior, arribo a la conclusión de que la CSJN se excede en el ejercicio de esas facultades reglamentarias e invade las que son propias y exclusivas del legislador, porque ha generado un nuevo cauce procesal que contraría o modifica el derecho positivo vigente. La consecuencia de esta transgresión normativa es que, al tiempo que vuelve operativa según pautas discresionales una legitimación extraordinaria en favor de las asociaciones civiles, restringe la posibilidad de quien procura la defensa de sus propios derechos.

Siendo coherentes con la legislación vigente expuesta, a lo sumo podría encuadrarse a la participación de las asociaciones civiles como una mera gestión procesal en los términos del artículo 48 del CPCCN, ${ }^{95}$ con las consecuentes limitaciones que dicho instituto procesal prevé.

En todo caso, queda una vez más en evidencia la inexorable necesidad de disposiciones legales claras y precisas para que una asociación civil impulse un

93 "Artículo 49.- Presentado el poder y admitida su personería, el apoderado asume todas las responsabilidades que las leyes le imponen y sus actos obligan al poderdante como si él personalmente los practicare".

94 "Artículo 52.- Sin perjuicio de la responsabilidad civil o criminal por el ejercicio del mandato, el mandatario deberá abonar a su poderdante las costas causadas por su exclusiva culpa o negligencia, cuando éstas fueran declaradas judicialmente. El juez podrá, de acuerdo con las circunstancias, establecer la responsabilidad solidaria del mandatario con el letrado patrocinante".

95 "Artículo 48.- Cuando deban realizarse actos procesales urgentes y existan hechos o circunstancias que impidan la actuación de la parte que ha de cumplirlos, podrá ser admitida la comparecencia en juicio de quien no tuviere representación conferida. Si dentro de los CUARENTA (40) días hábiles, contados desde la primera presentación del gestor, no fueren acompañados los instrumentos que acrediten la personalidad o la parte no ratificase la gestión, será nulo todo lo actuado por el gestor y éste deberá satisfacer el importe de las costas, sin perjuicio de su responsabilidad por el daño que hubiere producido [...]". 
proceso de tutela individual homogénea de manera respetuosa con el ordenamiento jurídico argentino.

\section{Conclusión}

En diferentes momentos a lo largo del presente estudio ha quedado en evidencia el perfil activista que la CSJN adoptó en el campo de los procesos colectivos, especialmente en los relativos a supuestos de tutela individual homogénea, al haberles otorgado legitimación extraordinaria a asociaciones civiles.

La propia Corte es quien reconoce la necesidad de la existencia de legislación formal que regule la materia analizada a lo largo de estas páginas. Ya en el considerando 12 de Halabi, la Corte lo expresó así

$[\mathrm{N}]_{\mathrm{o}}$ hay en nuestro derecho una ley que reglamente el ejercicio efectivo de las denominadas acciones de clase en el ámbito específico que es objeto de esta litis. Este aspecto resulta de gran importancia porque debe existir una ley que determine cuándo se da una pluralidad relevante de individuos que permita ejercer dichas acciones, cómo se define la clase homogénea, si la legitimación corresponde exclusivamente a un integrante de la clase o también a organismos públicos o asociaciones, cómo tramitan estos procesos, cuáles son los efectos expansivos de la sentencia a dictar y cómo se hacen efectivos.

Sin embargo, puedo afirmar que se desdice con sus actos intentando justificar el dictado de fallos y normas en contra de lo dispuesto por el ordenamiento jurídico argentino con una supuesta mora inconstitucional ${ }^{96}$ del legislador que no reglamenta, principalmente, al artículo 43 de la $\mathrm{CN}$ según cómo debería ser a la luz de la interpretación del alto tribunal.

Resulta de gran interés la opinión de Sagüés (2013) sobre este punto, quien, comentando Halabi, sostiene:

La Corte (voto mayoritario) señala que la acción de clase es un imperativo constitucional, y que el silencio legislativo al regularla importa inconstitucionalidad por omisión. Sin embargo, la lectura de las actas de la convención reformadora de 1994 no evidencia esa voluntad del constituyente, por lo que no existe una directriz constitucional clara a cumplir obligadamente por el legislador, requi-

96 CSJN, Halabi, considerando 12: "Frente a esa falta de regulación -la que, por lo demás, constituye una mora que el legislador debe solucionar cuanto antes sea posible, para facilitar el acceso a la justicia que la Ley Suprema ha instituido-, cabe señalar que la referida disposición constitucional es claramente operativa y es obligación de los jueces darle eficacia [...]". 
sito indispensable para que se perfile la referida inconstitucionalidad omisiva. (cap. XII, § 7.2)

Además de la supuesta operatividad de la mencionada cláusula constitucional, este "pequeño desliz" de arrogarse funciones legislativas también es justificado por la Corte debido a los importantes beneficios que teóricamente se obtendrían gracias a la tramitación de procesos colectivos.

Para los casos de tutela individual homogénea, la CSJN puso el foco en la inviabilidad económica de afrontar un proceso judicial en solitario por cada uno de los potenciales demandantes en este tipo de casos, por resultar, en muchas ocasiones, mayor el costo de la tramitación del expediente que el potencial beneficio en caso de obtener una sentencia favorable. Así lo expresó, entre otros, en el considerando 13 de Halabi al afirmar que "es exigible que el interés individual considerado aisladamente, no justifique la promoción de una demanda, con lo cual podría verse afectado el acceso a la justicia”.

La doctrina también ha realizado esfuerzos para avalar este camino procesal. Con una finalidad pedagógica, Salgado distingue en dos categorías los fundamentos ${ }^{97}$ del apoyo a la tutela individual homogénea en: 1) motivos de orden práctico y de ajuste del sistema procesal; e 2) implicancias políticas, sociales y económicas.

Dado el grado de avance del presente trabajo, para no introducir un nuevo elemento cuyo desarrollo implicaría un esfuerzo que me apartaría del eje central, solo haré mención a las referidas ventajas pragmáticas, sin desconocer que existen muchas otras.

Entre ellas podemos encontrar la economía de insumos materiales y humanos al condensar innumerables procesos en un solo expediente judicial, la posibilidad de llevar adelante reclamos de pequeña cuantía -impracticables en un sistema tradicional- y el consecuente desincentivo de realizar las prácticas antijurídicas masivas que motivarán a aquellos a litigar, la posibilidad de brindar herramientas al servicio de administración de justicia para evitar su colapso, entre otras. ${ }^{98}$

A pesar de los aparentes aspectos positivos enunciados, la conveniencia de estas ventajas no cambia el hecho de que nuestro andamiaje constitucional pre-

97 Cfr. Salgado (2011, pp. 8-23). Para comprender ventajas y riesgos posibles, se recomienda también la lectura de los trabajos de Cazaux (2019) y de Maqueda Fourcade (2018).

98 Además de Salgado (2011), sugiero la lectura sobre las ventajas del proceso colectivo en Verbic (2017, pp. 264-284). 
vé que la regulación de alcance general de los derechos sea dictada por los poderes legislativos nacional y provinciales, según corresponda, salvo los supuestos expresamente establecidos que habilitan a los poderes ejecutivos federal y locales a dictar normas de naturaleza semejante. Nuevamente, reitero que el proceso civil, como concreción del derecho de peticionar ante las autoridades, no debe ser regulado por cualquier ente gubernamental so pretexto de aparentes ventajas, sino únicamente por quienes están expresamente empoderados a tal fin.

Por ello, si bien son innumerables los beneficios hipotéticos que se plantean, lo cierto es que la Corte no se encuentra facultada para poder generar válidamente las normas procesales que regulen este tipo de cauce colectivo, por lo cual debería respetar el ejercicio de quienes sí poseen las atribuciones constitucionales necesarias para ello. ${ }^{99}$

En rigor de verdad, la Constitución Nacional solo le otorga a la CSJN atribuciones reglamentarias en torno a su funcionamiento interno, y las posibilidades en cuanto a la regulación de derechos solo están previstas de manera particular para las causas en las que interviene.

Sostiene Calvinho (2013):

a primer golpe de vista, el activismo judicial puede parecer atractivo si atendemos sólo a la meta -o sea, si asumimos una postura exclusivamente finalistapues sus resultados se obtienen merced a un intervencionismo judicial en el método. (p. 15)

Lo paradójico de este supuesto de activismo es que no se limita a una intervención en el proceso ejerciendo el rol que les corresponde a las partes, sino que ha desplazado los límites de sus avances de manera más feroz porque también se entromete en las atribuciones específicas del legislador.

A modo de crítica, afirma Jiménez (2010, p. 130) que "[e]l juez liberal y garantista se limita modestamente a pretender hacer efectivo el derecho positivo

99 Resulta muy interesante la opinión de Dalla Vía (2009) al comentar Halabi, quien afirma que: "No nos parece, en cambio, tan adecuado que un mecanismo procesal tan complejo en cuanto a su funcionamiento se haya adoptado por vía pretoriana, considerándola como una suerte de garantía implícita entre las formas de amparo colectivo. [...] El caso actual es distinto, ya que aquí la Corte crea un mecanismo procesal más que un derecho sustancial, aun cuando considera en los fundamentos de la sentencia que el amparo colectivo del art. $43 \mathrm{CN}$ contiene de modo implícito el mecanismo procesal adoptado. Nos parece que la situación se asemeja más al caso 'Sejean', de 1985, que a la de los casos 'Siri' (1957) y 'Kot' (1958). Efectivamente, en 'Sejean' la Corte creó el divorcio vincular, a pesar de que la Ley de Divorcios vigente solamente autorizaba la separación personal de los cónyuges”. 
entre los ciudadanos, a aplicar la ley" valiéndose de los elementos aportados por las partes procesales.

En este estudio he podido vislumbrar un activismo que va mucho más allá de los supuestos por los que, como afirma Alvarado Velloso (2010, p. 1212), "se elimina la idea de proceso como método de discusión y se lo utiliza como medio de investigación”.

He aquí, probablemente, la mencionada corriente procesal en su estado más puro, por la cual el Poder Judicial, más allá de la intensidad con la que interviene en el marco del proceso, no solo se aparta de las disposiciones legales vigentes, sino que también las reemplaza por otras de creación propia. En otras palabras, no contentos con limitarse a la "modesta" tarea de aplicar la ley entre las partes, no aplica normas imperantes, las deroga y/o crea otras nuevas.

La mera excusa de alcanzar supuestos beneficios no habilita una intromisión ilegítima, que quiebra con las disposiciones constitucionales que prevén la necesidad de leyes formales para la regulación del proceso judicial. Admitir lo contrario es permitir un desplazamiento inválido de los límites de la división de poderes, lo cual afecta principios republicanos básicos que resguardan los mecanismos previstos para la salvaguarda de garantías fundamentales. Como bien recuerda Gelli (2018a, p. 33), "[e]n el sistema de la república democrática, la separación de poderes fue dispuesta para controlar el poder, posibilitar la libertad y garantizar los derechos de las personas".

Existen innumerables ejemplos de derecho comparado y legislación provincial vigente que dan muestras de que los procesos de tutela individual homogénea pertenecen al ámbito de las atribuciones de los poderes legislativos. ${ }^{100}$

La propia Corte, desde Halabi, recuerda esas experiencias normativas comparadas entre los incisos 17 y 18 del fallo. Respecto a los ejemplos de jurisdicciones locales, según explica Salgado (2011)

\begin{abstract}
Algunos Estados provinciales han regulado mecanismos de tutela colectiva, entre los cuales se destacan los derechos individuales homogéneos. El común denominador, aun cuando existan esfuerzos más meritorios que otros, es que resultan incompletos o internamente discordantes. [...] Un primer grupo de regulaciones, más avanzadas, son aquellas que específicamente se han ocupado de hablar de los derechos individuales homogéneos como una categoría de tener un mecanismo de tutela específico. [...] En una línea menos rigurosa, encontramos regulaciones provinciales que se han ocupado de regular procesos colectivos orientados a la defensa de los derechos de los consumidores o usuarios -sin
\end{abstract}

100 Sobre la experiencia internacional, se recomiendan las siguientes lecturas: Bianchi (2001; 2002, pp. 93-130); González Campaña (2018, p. 38); Lorenzetti (2017, pp. 107-118); Salgado (2019); Verbic 
especificar la divisibilidad o indivisibilidad de su objeto- que, según cuál sea la interpretación que de ellos hagan los operadores, podrían permitir la tramitación de pretensiones individuales homogéneas". (pp. 240-241) 101

Los representantes del pueblo que se dan cita en el Congreso de la Nación no han logrado todavía encontrar una fórmula que pueda hacer realidad este nuevo camino jurisdiccional. Sin embargo, mientras que para algunos esta aparente carencia normativa resulta ser una omisión inconstitucional, para los que creemos en la forma republicana de gobierno es, sin más, el libre juego de la división de poderes en un Estado democrático que no puede ser soslayado por la judicatura.

Quienes sostienen las banderas del activismo judicial, quizás con intenciones loables mal encauzadas, ven solo un formalismo inútil en quienes velan por la división de poderes. Quizás convenga reflexionar en torno a lo afirmado por Calvinho (2012), quien sostiene

Una democracia evolucionada, abonada con el aporte del constitucionalismo moderno, la división de funciones del poder y su intercontrol -pilares del republicanismo-, el sometimiento del poder a la ley -que surge del Estado de derecho- y la preocupación social por fortalecer sus instituciones, brinda una plataforma que coadyuva a la realización plena del ser humano. (p. 69)

Así, defender una operatividad automática del artículo 43 de la $\mathrm{CN}$, sin legislación proveniente de las autoridades envestidas constitucionalmente y dejando en manos de la discrecionalidad judicial los derechos de las partes en un litigio, equivale a no respetar el proceso como garantía inherente al ser humano, lo cual lesiona derechos como el de peticionar ante las autoridades, el de acceso a la justicia y el de defensa en juicio. ${ }^{102}$

Sin lugar a dudas, vale la pena una discusión legislativa seria para procurar un sistema de tutela individual homogénea.

Lo que es seguro, tal cual afirma Alvarado Velloso (2010), es que

(2017, pp. 239-263); entre otros.

101 En Giannini y Verbic (2017, pp. 123-888) se analiza la situación de la Ciudad Autónoma de Buenos Aires y de 18 provincias en cuanto al grado de desarrollo de supuestos de justicia colectiva. En caso de proceder a su lectura, debe tenerse en cuenta que para la provincia del Chaco correspondería una actualización a la descripción allí realizada porque su Legislatura aprobó la Ley 3325-B de Juicios Civiles y Comerciales por Jurados, BO 03/02/2021, que, entre otros, regula diversos supuestos de procesos colectivos. Lo propio sucede en la Ciudad Autónoma de Buenos Aires, que aprobó la Ley 6407 del Código Procesal para la Justicia en las Relaciones de Consumo en el ámbito de la Ciudad Autónoma de Buenos Aires, BO 19/03/2021.

102 Cfr. Calvinho (2013, p. 17). 
los jueces no pueden aspirar a equipararse a los comisarios de policía -por buenos y justicieros que éstos pudieren ser- en aras de lograr una eficiencia que no encuentran respetando la Constitución. No es eso lo que precisamente juraron cuando fueron investidos de sus cargos. (p. 1212)

A ellos, y a todos los que deseen aproximarse al mundo de la justicia colectiva, vale la pena recordarles, con palabras del mismo autor, "que el proceso es garantía de los derechos individuales y, en especial, del de la libertad que, aun cuando implícito, es el máximo valor de la norma fundamental" (Alvarado Velloso, 2010, p. 1212).

\section{Bibliografía}

Alvarado Velloso, A. (2009). Sistema procesal. Garantía de libertad (Tomo I). Rubinzal- Culzoni. Alvarado Velloso, A. (2010). El garantismo procesal. La Ley, 2010-F, 1212.

Azar-Baud, M. J. (25 de abril de 2016). El arte de evitar el escándalo jurídico. La Ley, 3.

Bianchi, A. B. (2001). Las acciones de clase. Una solución a los problemas procesales de la legitimación colectiva a gran escala. Ábaco.

Bianchi, A. B. (2002). Control de constitucionalidad. (2a ed., Tomo II). Ábaco.

Briseño Sierra, H. (1966). Excepciones Procesales. Revista de la Facultad de México, XVI(63-64), 255-351.

Calvinho, G. (2012). El proceso con derechos humanos. Método de debate y garantía frente al poder. Universidad del Rosario.

Calvinho, G. (2013). La procedimentalización posmoderna. Revista del Instituto Colombiano de Derecho Procesal, (39), 11-31.

Camps, C. E. (2019). El anteproyecto de Ley de Procesos Colectivos de Justicia 2020 frente a la eficacia. La Ley, RDAmb 57, 22/03/2019, 15, AR/DOC/3803/2018.

Catalano, M. (17 de junio de 2015). Los derechos colectivos en el título preliminar del nuevo Código Civil y Comercial de la Nación. La Ley, 49, AR/DOC/4701/2015.

Catalano, M. (2018). El anteproyecto de ley de procesos colectivos. Justicia 2020. La Ley, 2018C, 1244, AR/DOC/1335/2018.

Cazaux, D. H. (2019). Análisis económico de los procesos colectivos en la Argentina. La Ley, SJA 22/05/2019, AR/DOC/3878/2018.

Couture, E. J. (2010 [1948]). Obras (5ª ed., Tomo II). Estudios de Derecho Procesal Civil (Vol. 1). La Constitución y el Proceso Civil. La Ley.

Couture, E. J. (2010 [1950]). Obras (5a ed., Tomo II). Estudios de Derecho Procesal Civil (Vol. 3). El juez, las partes y el proceso. La Ley.

Dalla Vía, A. R. (2009). El activismo de la Corte Suprema puesto en defensa de la privacidad. Jurisprudencia Argentina, 2009-II, 509, 0003/014388. 
Dirección de Servicios Legislativos del Honorable Congreso de la Nación. (2019). Dossier legislativo. Derechos de incidencia colectiva, VII (167).

Gelli, M. A. (2018a). Constitución de la Nación Argentina. Comentada y concordada (5a ed., Tomo I). Thomson Reuters La Ley.

Gelli, M. A. (2018b). Constitución de la Nación Argentina. Comentada y concordada (5ª ed., Tomo II). Thomson Reuters La Ley.

Giannini, L. J. (2018). Análisis crítico del Anteproyecto de Ley de Procesos Colectivos del Ministerio de Justicia de la Nación. La Ley, 2018-D, 526, AR/DOC/1425/2018.

Giannini, L. J. y Verbic, F. (Dirs.). (2017). Los procesos colectivos y acciones de clase en el derecho público argentino. Rubinzal-Culzoni.

González Campaña, G. (7 de febrero de 2018). Las acciones de clase en Estados Unidos y los procesos colectivos de Argentina: dos modelos antagónicos. La Ley, 38, AR/DOC/4370/2017.

Gozaíni, O. A. (2018). Legitimación, capacidad y representación en juicio. Problemas de articulación del Código Civil y Comercial de la Nación con los Códigos Procesales en lo Civil y Comercial. Rubinzal-Culzoni.

Halabi, E. y Díaz Cisneros, A. P. (12 de junio de 2019). Diez años del fallo "Halabi”. Diez años de acciones de clase. La Ley, 3, AR/DOC/1263/2019.

Jiménez, M. E. (2010). Poderes instructorios del juez. Medidas para mejor proveer. Activismo judicial versus garantismo. Nuevas tendencias y recaudos. CSJN. LLC, 130.

Lorenzetti, R. L. (2010). Justicia colectiva. Rubinzal-Culzoni.

Lorenzetti, R. L. (Dir. gral.). (2014). Código Civil y Comercial Explicado. Doctrina - Jurisprudencia. Título preliminar. Rubinzal-Culzoni.

Lorenzetti, R. L. (2017). Justicia colectiva (2a ed.). Rubinzal-Culzoni.

Maqueda Fourcade, S. (2018). Economía de los procesos colectivos. El sistema de procesos colectivos como solución estatal a las "fallas" del mercado de procesos individuales. La Ley, 2018-B, 1051, AR/DOC/733/2018.

Montero Aroca, J., Gómez Colomer, J. L. y Montón Redondo, A. (2001). El nuevo proceso civil, Ley 1/2000. Tirant Lo Blanch.

Morello, A. M., Sosa, G. L. y Berizonce, R. O. (2015). Códigos Procesales en lo Civil y Comercial de la Provincia de Buenos Aires y de la Nación (4a ed., Tomo V). Abeledo Perrot.

Palacio, L. E. (2017). Derecho Procesal Civil (4a ed.). Abeledo Perrot.

Picasso, S. y Vázquez, R. A. (Dirs.) (2013). Ley de Defensa del Consumidor comentada y anotada (Tomo I Parte General). La Ley.

Rodríguez Mancini, J. (2016). Derechos de incidencia colectiva (según el art. 14 del Anteproyecto de CCC) y relaciones laborales. La Ley, 227, AR/DOC/352/2016.

Sacristán, E. (2020). La Corte Suprema como titular de poder reglamentario. Revista Jurídica Austral, 1(2), 499-530. https://doi.org/10.26422/RJA.2020.0102.sac.

Sagüés, N. P. (2009). La creación judicial del "amparo-acción de clase" como proceso constitucional. Jurisprudencia Argentina, 2009-II-627, 0003/014385.

Sagüés, N. P. (12 de septiembre de 2018). El trámite del amparo colectivo nacional y los roles nomogenéticos de la Corte Suprema. Jurisprudencia Argentina, 80, AR/DOC/3413/2018, pto. IV Sagüés, N. P. y Sagüés, M. S. (2013). Dinámica actual del derecho procesal constitucional. En Vigo, R. L. y Gattinoni de Mujía, M. (Dirs.), Tratado de Derecho Judicial (Tomo I Teoría General), Abeledo Perrot. 
Salgado, J. M. (2011). Tutela individual homogénea. Astrea.

Salgado, J. M. (25 de abril de 2016). La Corte legisla sobre los procesos colectivos. La Ley, 4.

Salgado, J. M. (2019). Conflicto masivo y proceso (Ponencia general). Congreso Nacional de Derecho Procesal, San Juan, Argentina.

Tobías, J. W. (2018). Tratado de Derecho Civil. Parte General. La Ley.

Verbic, F. (2017). Manual de introducción a los procesos colectivos y las acciones de clase. En Fandiño, M. y González, L. (Dirs.), Diálogo multidisciplinario sobre la nueva Justicia Civil en Latinoamérica (pp. 219-379). Centro de Estudios de Justicia de las Américas.

Verbic, F. (2018). El anteproyecto de Ley de Procesos Colectivos impulsado por el Ministerio de Justicia. La Ley, 2018-C, 1236, AR/DOC/1336/2018.

Verbic, F. y Sucunza, M. A. (18 de mayo de 2016). Postulación de pretensiones colectivas a la luz de la reciente acordada de la Corte Suprema. La Ley, 1, AR/DOC/1275/2016.

Ylarri, J. S. (2014). La legitimación de las asociaciones de consumidores y usuarios en las acciones de clase: el precedente PADEC. Revista de Derecho Administrativo, 2014-92, 355-363, AR/DOC/4899/2014.

\section{Legislación citada}

\section{Normas nacionales}

Decreto 1798/1994, reglamentario de la Ley 24240, BO 18/10/1994.

Ley 17454 de Código Procesal Civil y Comercial de la Nación, BO 07/11/1967.

Ley 23551 de Asociaciones Sindicales, BO 22/04/1988.

Ley 26122 de régimen legal de los decretos de necesidad y urgencia, de delegación legislativa y de promulgación parcial de leyes, $\mathrm{BO}$ 28/07/2006.

Ley 26994 de Código Civil y Comercial de la Nación, BO 08/10/2014.

Resolución del Ministerio de Justicia y Derechos Humanos de la Nación 2017-1026-APN-MJ de Creación de la Comisión Redactora del Anteproyecto de Ley de Procesos Colectivos, BO 22/12/2017.

\section{Normas provinciales}

\section{Ciudad Autónoma de Buenos Aires}

Ley 6407 del Código Procesal para la Justicia en las Relaciones de Consumo en el ámbito de la Ciudad Autónoma de Buenos Aires, BO 19/03/2021.

\section{Provincia del Chacho}

Ley 3325-B de Juicios Civiles y Comerciales por Jurados, BO 03/02/2021, que, entre otros, regula diversos supuestos de procesos colectivos. 


\section{Jurisprudencia citada}

\section{Corte Interamericana de Derechos Humanos}

Opinión Consultiva OC-6/86. La expresión 'leyes' en el artículo 30 de la Convención Americana sobre Derechos Humanos. Solicitada por el Gobierno de la República Oriental del Uruguay, 09/05/1986, Serie A, $\mathrm{N}^{\circ} 6$.

Pollo Rivera y otros vs. Perú, (fondo, reparaciones y costas), 21/10/2016, Serie C, Nº 319.

\section{Corte Suprema de Justicia de la Nación}

Acordada 12/2016, 05/04/2016, AR/LCON/75EC.

Acordada 32/2014, 1/10/2014, AR/LCON/6CE4.

Asociación Civil DEFEINDER c/Telefónica de Argentina S.A. s/proceso de conocimiento, 27/11/2014, Nro. Interno: A.803. XLVI.

Asociación Sepa Defenderse c/Secretaría de Energía de la Nación y otros s/amparo colectivo, 26/12/2018, La Ley, AR/JUR/79291/2018.

Centro de Estudios para la Promoción de la Igualdad y la Solidaridad y otros c/Ministerio de Energía y Minería s/amparo colectivo, 18/6/2016, Nro. Interno: FLP 8399/2016/CS1, Id SAIJ: FA16000098.

Halabi, Ernesto c/Poder Ejecutivo Nacional - ley 25.873 - dto. 1563/04 s/amparo ley 16.986, 24/02/2009, Fallos: 332:111, Nro. Interno: H.270. XLII.

Kersich, Juan Gabriel y otros c/Aguas Bonaerenses S.A. y otros s/amparo, 02/12/2014, Nro. Interno: CSJ 42/2013 (49-K).

Kot, Samuel S.R.L. s/recurso de hábeas corpus, 05/09/1958, Fallos: 241:291

Mendoza, Beatriz Silvia y otros c/Estado Nacional y otros s/daños y perjuicios (daños derivados de la contaminación ambiental del Río Matanza - Riachuelo), 20/06/2006, Fallos: 329:2316.

Municipalidad de Berazategui c/Cablevisión S. A. s/amparo, 23/09/2014, Nro. Interno: M. 1145. XLIX., Id SAIJ: FA14000143.

PADEC c/Swiss Medical S.A. s nulidad de cláusulas contractuales, 21/08/2013, Nro. Interno: P.361. XLIII, Id SAIJ: FA13000127.

Sindicato Único de Trabajadores Privados de la Libertad Ambulatoria c/Estado Nacional - Ministerio de Justicia y Derechos Humanos de la Nación y otros s/amparo, 10/11/2015, Nro. Interno: CSJ $841 / 2013$ (49-S) /CS1.

Siri, Ángel s/interpone recurso de hábeas corpus, 27/12/1957, Fallos: 239:461. 
